\title{
Explaining the Link between Technostress and Technology Addiction for Social Networking Sites: A Study of 'Distraction' as a Coping Behavior
}

\begin{abstract}
Research shows that when individuals experience stress from using social networking sites (SNS), they may respond by using it less. However, practical findings shows that counterintuitively, when individuals are stressed from using SNS they may use it even more and be addicted to using it. The objective of this paper is to investigate under what conditions stress from the use SNS is linked to addiction to the use of the same SNS. Integrating three theoretical strands - the concept of feature rich IT, the theory of technology frames, and distraction as a coping behavior - we theorize two types of coping behaviors in response to stressors experienced from use of SNS. These are, distraction through use of the same SNS, and distraction through activities outside the use of the SNS. We hypothesize relationships between stressors from SNS use, the two coping behaviors and SNS addiction. We further articulate the role of SNS use habit. We test the hypotheses through a three-wave survey of 444 Facebook users with data collected at three different points in time. The paper's contributions are to theorize and empirically validate - the psychological concept of distraction as a coping behavior in response to stress from use of SNS, and in doing so, explain why there may be a link between technostress from and technology addiction to use of SNS.
\end{abstract}

Keywords: technostress, technology addiction, coping, distraction, feature rich IT, technology framing, social networking sites, IT use habit 


\section{INTRODUCTION}

The use of IT is a source of stress, namely, technostress (Ayyagari et al. 2011; Tarafdar et al. 2007). Research shows that use of specific applications such as social networking sites (SNS) is associated with stress (e.g. Maier et al. 2015b). Individuals respond to stressful situations by engaging in coping behaviors (Lazarus and Folkman 1984). One such coping behavior is to avoid the stressful situation. In the case of stress from the use of SNS, research shows that when individuals perceive their use as stressful, they often reduce the extent of use or even stop using it altogether (Maier et al. 2015a). However, intriguing and counter-intuitive research findings also show that even when individuals are stressed from using them, they continue to use it (Maier et al. 2015b). Practical observations also support this finding, as shown by the following exemplified scenario ${ }^{1}$ experienced by many users of SNS:

Facebook wears me out. But I was on the bus for a few hours yesterday, so I thought: Oh, I'll look at Facebook for a few minutes. Two hours later I came up from the 'deep' for air. I realized I had been - 1) giving advice to a friend who is a single dad and who posted to ask what to cook for his teenaged daughter who apparently hates to eat; 2) posting a selfie; 3) arguing heatedly about Brexit; 4) playing Candy Crush Saga, which I don't really like, but a friend wanted to play it because she was upset with her boyfriend; 5) looking at pictures of a group of friends holidaying on the beaches in Bali. Before I knew it, I had spent two hours on Facebook!

We are beginning to observe a blurring between the stress caused by use of applications such as SNS, and addictive or compulsive use of these very applications to keep up with them. Studies indicate that even as individuals find it exhausting to respond to posts in SNS, they find it increasingly difficult to turn away from it (Weinschenk 2012). Hence, even when individuals are stressed from use of SNS, they may be addicted to the same SNS.

This phenomenon poses both research and practical challenges. The research challenge is that it contradicts what we theoretically and empirically know about technostress and addiction

\footnotetext{
${ }^{1}$ This scenario is culled from a number of contemporary accounts and commentaries of the use of social networking applications such as Facebook, for example - see https://www.dailydot.com/debug/beyond-facebookanxiety/ and http://www.pewinternet.org/2015/01/15/psychological-stress-and-social-media-use-2/, and from experiences of associates and friends.
} 
from the use of SNS, namely that technostress is associated with reduced use and hence should not be associated with addiction (Maier et al. 2015a; Turel et al. 2011). According to prevailing understanding in the literature, individuals stressed by using SNS are not addicted to them. The practical challenge is that both technostress and technology addiction have negative organizational and societal impacts (Tarafdar et al. 2015). The significance and urgency of concerns regarding adverse impacts of use of technology can be gauged by the fact that research-funding councils have begun to prioritize the funding of research that focuses on them. For instance, the European Union's largest scientific funding program, the European Research Council, encourages funding applications that address the 'challenges, and sometimes threats, that need to be addressed to ensure that technological innovations go hand in hand with societal needs and expectations ${ }^{2}$. This combined research and practical challenge informs our research question:

\section{How and why is stress from the use of a particular SNS associated with addiction to}

\section{the same SNS?}

Research relevant to this phenomenon shows a number of important gaps. Firstly, we know from the psychology literature that people who are stressed by work and family situations can become addicted to behaviors such as gambling (Tang and Oei 2011) in an effort to 'escape' (Lazarus 1966). However, in such a case, the individual is addicted to a behavior that is unconnected to the situation that is causing stress. Secondly, the IS literature indicates that individuals may cope with the disruptive and stressful effects of IT by avoiding or stopping its use (Beaudry and Pinsonneault 2010; Stein et al. 2015). Neither of these literatures explain how and why individuals experiencing stress from using a particular IT can become addicted to using the same IT.

\footnotetext{
${ }^{2}$ The details can be found at http://ec.europa.eu/research/participants/data/ref/h2020/wp/2016_2017/main/h2020-wp1617-leit-ict_en.pdf
} 
We draw from three theoretical perspectives in this paper. One, the theory of technology frames suggests that the user cognitively represents the IT that he or she uses, in different ways (e.g. Orlikowski and Gash 1994; Vaast and Walsham 2005). Two, the concept of feature rich IT (e.g. Lyytinen and Yoo 2002) describes IT that has many features and functionality and can be used in a variety of different ways and for different purposes. For example, individuals can use SNS to follow friends' activities, chat with friends, or post pictures about daily activities (Koroleva et al. 2011). Three, in the psychological stress literature, 'distraction' is a coping behavior in response to stress creating situations, through which the individual diverts his or her attention from that situation (Cooper et al. 2001; Traeger 2013). Such diversion takes the user 'away' from the stressful situation into a new satisfactory situation (Lazarus 1966). We theorize that distraction can be used as a coping mechanism to deal with stressors from the use of SNS. We integrate these perspectives to conceptualize and empirically validate a link between stress creating conditions from and addiction to SNS. Our data draws from a three-wave survey of 444 Facebook users with data collected at three different points in time.

As contributions to the literature, the paper introduces, theoretically develops, and empirically validates the concept of distraction as a coping behavior to deal with stress from use of SNS. It further develops and validates a novel explanation linking conditions creating stress from use of SNS, distraction through the use of the same SNS and SNS addiction. Through these contributions, it explains why and how individuals who experience stress-creating conditions from the use of SNS can be addicted to the same SNS.

The rest of the paper is structured as follows. In Section 2, we provide the literature background covering relevant studies. In Section 3, we theorize distraction as a coping behavior to deal with stress from use of SNS, and develop our research hypotheses. In Section 
4, we describe the study's methods. We conclude in Section 5 with a discussion of the theoretical contributions, together with practical and policy related implications of our study.

\section{LITERATURE BACKGROUND}

In this section, we discuss the literature that informs our study. We first discuss the underlying work on technostress and IT addiction. We then review the IS literature on individuals' coping actions in the context of IT use.

\subsection{Technostress}

Technostress is the stress that individuals experience due to their use of IT. It has been examined both in organizational and non-organizational contexts of use of IT. The early studies were in the organizational use of IT. They provide theoretical and empirical evidence that conditions that create technostress, or techno-stressors, constitute technology use related demands (Ayyagari et al. 2011; Tarafdar et al. 2007). The consequences of technostress for the individual include reduced job satisfaction, innovation, productivity, end user satisfaction, and performance (Ragu-Nathan et al. 2008; Tarafdar et al. 2007; Tarafdar et al. 2010), and increased burnout (Ayyagari et al. 2011; Maier et al. 2019). In an experiment relating to work done on a computer, stress from simulated interruptions led to a decline in performance on that task (Galluch et al. 2015).

Subsequent studies have focused on technostress in the non-organizational context. In particular, research has examined technostress from the voluntary use of social networking sites (SNS) showing that individuals find the use of SNS such as Facebook, stressful. There are six conditions, or SNS stressors, under which the voluntary use of SNS can create stress for individuals (Maier et al. 2015b). 'Invasion' reflects the stress creating condition wherein individuals feel that their personal life is being invaded by SNS because they use SNS in inopportune situations such as during vacations. 'Pattern' describes the stressor the individual experiences when he or she adapts his or her use of SNS to conform to his or her friends' use. 
Such action can come from, among others checking updates several times a day, to keep up with friends' postings and to inform them through one's own. 'Social overload' describes the stress that users feel because they respond to too many requests through the SNS for social support, address friends' problems through SNS posts, and pay attention to matters important to friends. They thus feel that they are experiencing excessive social demands through the SNS. 'Uncertainty' implies that there are constant changes and updates to the SNS applications that are stressful. 'Complexity' reflects the extent to which users perceive SNS as technically difficult to use because they do not understand enough about it. The difficulty could arise from, for instance, features that may be complicated to navigate through, such as privacy and data sharing features. 'Disclosure' refers to the stress-creating condition of individuals feeling that they get too much information on SNS, which prevents them from effectively using the application.

When individuals experience technostress, for example through social overload from using SNS, they become dissatisfied with the system or feel exhausted (Maier et al. 2015a). Practical observations (Gartner 2011) support these findings and suggest that individuals often report feeling fatigued and exhausted from using SNS. One way that individuals cope with stressors from use of SNS is by reducing the extent of use and even stopping use altogether (Maier et al. 2015b). However, research findings counter to this indicate that even when individuals are stressed by SNS, they may continue using it (Maier et al. 2015a) such that the they may get addicted. A theoretical explanation for these findings is missing - that is, we do not know why individuals can be stressed by and addicted to the same IT. We next turn to the literature on IT addiction to consider its key findings.

\subsection{Technology addiction}

Research in psychology conceptualizes behavioral addiction as losing control over and engaging excessively in a certain behavior, often to escape from real-world discomforts (Potenza 2006). Addiction can be with respect to (1) substances such as drugs; or (2) 
behaviors such as video gaming or pornography (Xu et al. 2012). The second type of addiction is salient to addiction in the context of IT use. Thus, research on IT addiction has focused on behavioral addiction. IT addiction is defined as various aspects of the individual's behavior with respect to IT use such as compulsive IT use, and IT use to the detriment of other important activities and things (Turel et al. 2011; Vaghefi et al. 2016).

Research on IT addiction has primarily examined addiction to the use of SNS applications in a non-organizational context (Turel 2015; Turel and Serenko 2012; Xu et al. 2012). Studies have examined various factors leading to IT addiction such as social-demographics (Young 1998), personality traits (Kim et al. 2008), technology characteristics (Griffiths and Parke 2002) and the extent to which IT satisfies individual needs (Xu et al. 2012). Research has also found that those with higher levels of addiction to a particular application consider that application to be more useful, easier to use and more fun to use, than non-addicts (Turel et al. 2011). What is missing, however, is an explanation of how and why users who are stressed from the use of a particular IT can also be addicted to the same IT. One possible reason could be that there is as yet only a fledgling understanding of how individuals cope with stress from use of IT. We next therefore, turn to the IS literature on coping.

\subsection{IS studies on coping}

Individuals respond to stressful or disturbing situations by engaging in coping behaviors.

These behaviors, triggered by stressors can be broadly classified as either problem or emotion focused (Lazarus 1966; Lazarus and Folkman 1984). Problem-focused coping involves efforts to alter or manage the stressful situation. Emotion-focused coping involves changing the way one thinks or feels about the stressful situation. It involves cognitive processes such as reappraisals and disengagement.

IS studies on coping can be classified in two streams, which we describe below and summarize in Appendix A. The first set of studies examines coping actions in response to 
demands due to implementation of new IS in the workplace, that the individual appraises as troubling. These coping actions are in reaction to what the individual perceives as new and discrepant in the new system, in terms of unfamiliar tasks and workflows that the IS requires him or her to do. Individuals respond through coping actions that include a number of behaviors. These could be general behaviors such as venting, seeking social support, and psychological distancing from the troubling situation (Beaudry and Pinsonneault 2010; Stein et al. 2015). They could also be behaviors relating to IS use, such as experimenting with new features to fit existing tasks and workflows, sticking to the minimum required use, and resisting/ avoiding use (Bala and Venkatesh 2015; Beaudry and Pinsonneault 2005; de Guinea and Webster 2013). Yet another set of behaviors relate to the alterations of the individual's task to suit the requirements of the new IS (Beaudry and Pinsonneault 2005).

The second set includes coping behaviors for responding specifically to technostress, that is stress from ongoing use of existing IS. This set is quite sparse. One study has identified moral disengagement from stress creating IS use security requirements in the workplace and avoiding compliance with them, as emotion-focused coping behaviors for stress from IS security (D'Arcy et al. 2014). Specifically for stress from voluntary and non-organizational use of SNS, discontinuing use altogether (Maier et al. 2015b) has been identified as a coping behavior. In an experimental study where individuals were asked to do an task and interrupted, control over the timing of interruption helped them to cope with the stress from the interruption (Galluch et al. 2015).

In the above studies, the coping behaviors are a mix of emotional and problem focused behaviors as we show in Appendix A.

\subsection{Summary}

From the above survey of the literature, we note the following. First, individuals experience both technostress and addiction from the non-organizational and voluntary use of SNS. 
Second, while a number of technostress creating conditions with regard to use of SNS, as well as antecedents of SNS addiction have been studied, there is no theoretical explanation for a possible relationship between them. Third, we note from IS coping studies that while a number of coping behaviors have been studied, they do not suggest that coping with stress from use of SNS is associated with addictive use of the same SNS.

\section{HYPOTHESES DEVELOPMENT}

Addressing these gaps in the literature, we next develop our research hypotheses as shown in Figure 1. In order to do so we draw from three theoretical perspectives as explained below.

The first is that of feature rich IT. SNS have a number of distinct characteristics. They can be used in many different ways because they provide a wide range of functionality and features. These include, among others, posting information and reacting to friends' postings, following others by reading their newsfeeds, communicating privately through one-one chats, engaging in social browsing by looking at profiles, browsing through newsfeeds and searching for friends, and playing games (Koroleva et al. 2011). They can be used for a wide range of tasks, such as to communicate and collaborate, and to create, organize/tag and manage or search for content. In the literature, such applications are referred to as feature rich IT. Feature rich IT are those that can be used in many different ways to support a rich and wide range of computing and communication tasks converging across social, recreational and work domains, because they have varied functionality and features (Lyytinen and Yoo 2002). SNS can thus be considered as feature rich. ${ }^{3}$ We consider SNS as feature rich IT. Because of their many and diverse functionalities, feature rich IT can be considered as 'technology-in-use'. This means that users appropriate the IT's features during use (DeSanctis and Poole 1994) in an adaptive and emergent manner (de Guinea and Markus 2009), in order to use the IT in

\footnotetext{
${ }^{3}$ For the purpose of anchoring our study, it is necessary to specify the particular feature rich IT (i.e. SNS) and develop hypotheses with respect to that anchoring.
} 
many different ways. They can do so by trying tasks using different features (Barki et al. 2007; Jasperson et al. 2005) and discovering new tasks using existing features (Desouza et al. 2007; Jasperson et al. 2005; Singletary et al. 2002). Drawing from the concept of feature rich IT, we thus suggest that SNS applications are technology-in-use wherein individuals use different features of and engage in different tasks by using the same SNS in an emergent manner.

Second, we consider the theory of technology frames, which suggests that the user's cognition toward an IT application shapes his or her use of it. Such cognition is captured by the theory of technology frames (Davidson and Pai 2004). Technology frames are cognitive representations of a particular IT held by individuals. They embody the individual's subjective and contextual assessment of the particular IT and its uses (Orlikowski and Gash 1994). Building on this notion, studies further suggest (e.g. Vaast and Walsham 2005) that the user can cognitively represent the same IT in different ways through different technology frames. This is referred to as the socio-cognitive approach to examining the use of IT. Drawing from this approach we thus suggest that SNS use is shaped by the user's cognitive representation of it and that the user can view the same SNS through different cognitive representations.

Thirdly, we draw from the psychology literature to consider the concept of 'distraction' as a coping behavior in response to stressors. Distraction is defined as coping behavior that is "employed to divert attention away from a stressor and towards other thoughts or behaviors" (Traeger 2013, p. 610) that are more pleasant. Considering that individuals can cognitively represent and use the same SNS in different ways, we investigate the possibility that the individual can use SNS to divert his or her attention. We thus introduce distraction as a coping behavior in response to the stressors from use of SNS. 


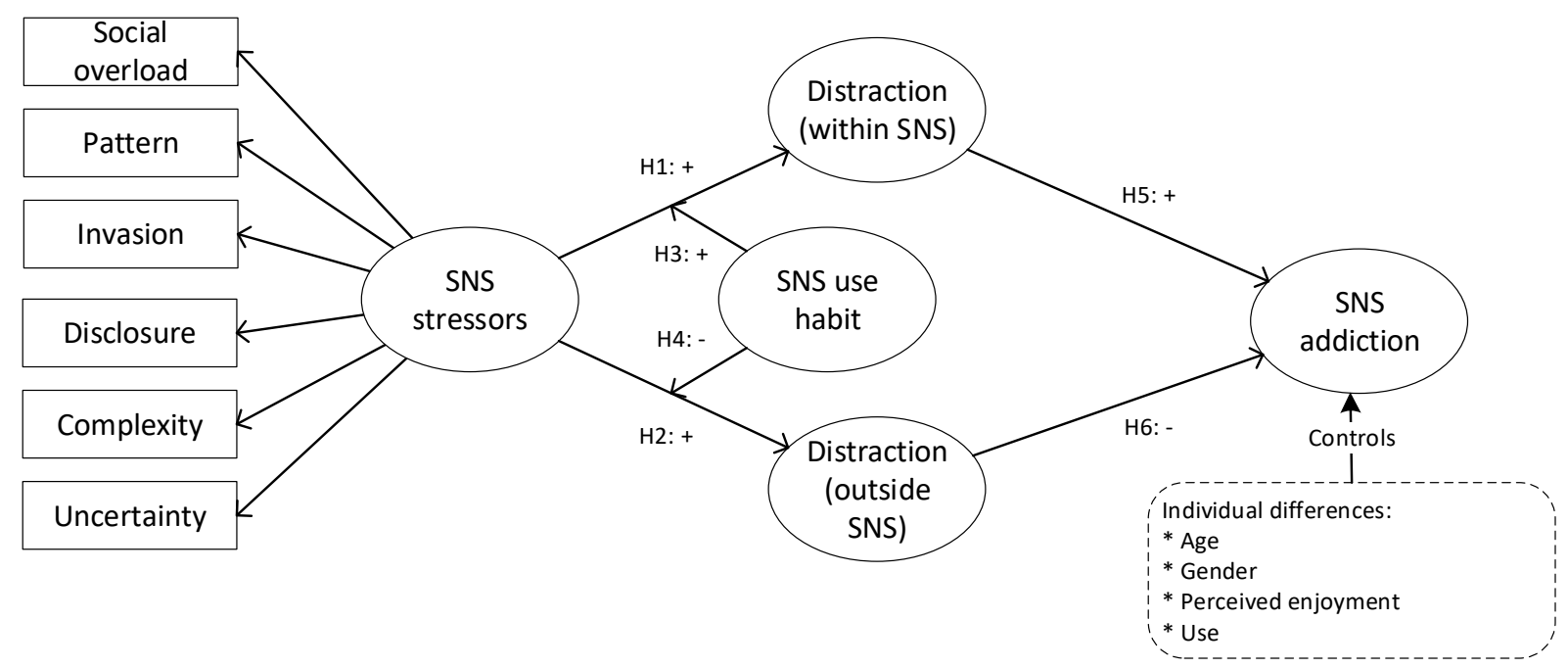

Figure 1: Research model

\subsection{Distraction as a coping behavior}

Distraction as a coping behavior implies that the individual copes with a stressful situation by diverting his or her attention away from it (Cooper et al. 2001; Lazarus 1966). It is a means of mental diversion by engaging in activities that are different from that associated with the stressful situation, so that the individual's mind is focused away from the situation. Coping through distraction takes the user psychologically and cognitively 'away' from the stressful situation into a more pleasant and enjoyable situation ${ }^{4}$. Distraction is often used in medical contexts to cope with pain and discomfort. The patient's attention is diverted away from a stressful medical procedure by asking him or her to focus on, for example, pleasant places using pictures, videos and music (Diette et al. 2003). Distraction is thus a way to cope with a stressful situation by directing the individual's attention away from it.

Drawing from the above, we theorize two kinds of distraction for coping with stress from the use of SNS. The first is that the individual diverts his or her attention away by doing activities other than using the SNS that is causing the stress. He or she does something different such as being with family or doing other hobbies. The second kind is that the individual diverts his or

\footnotetext{
${ }^{4}$ The word 'distraction' can have another meaning, which refers to confusion, bewilderment, lack of attention and frantic-ness. It can also be used in the sense of relieving monotony from something that is boring or tedious (Websters dictionary 1998). We do not use it in either of these connotations.
} 
her attention by using the same SNS that is causing the stress, but by using it in a different way. This is possible because SNS as feature rich IT offer a wide range of potential uses through varied functionality that can be flexibly and adaptively appropriated.

We next theoretically develop each of these distraction behaviors and frame hypotheses linking them with the technostress creators from the use of SNS, and with addiction to SNS.

\subsubsection{Distraction through technological framing - use of the same stress creating SNS}

The theory of technological framing suggests that IT users cognitively 'frame' or represent the IT they use in a certain way, which shapes their use (Orlikowski and Gash 1994, Davidson and Pai 2004). Building on this notion, studies further suggest the notion of 'rerepresentation' (Vaast and Walsham 2005) as follows. An IT use related cognitive representation that is disturbing (for example, stressful), makes the user uncomfortable with how he or she is using it (Vaast and Walsham 2005). This creates a cognitive dissonance that can serve as a trigger for use-related action that is intended to lead to a less disturbing cognitive representation about the IT. Such use-related action entails a change in the way the IT is used (Barley 1986). The user could, for instance, use the IT for a different task or activity. This different way of use of the same IT is associated with an altered and more pleasant cognitive representation, and then further shapes its use. This interplay between cognitive framing and use-related action is known as 're-representation' (Vaast and Walsham 2005). Drawing from this argument, we suggest that when users perceive use of SNS applications as stressful, they attribute a cognitive framing or representation of a 'stressor' to it. This cognitive representation, an uncomfortable one, triggers the user's coping action for change in use. Because the SNS application is feature rich, the user can use the same application to do something different that is not stressful, and gets diverted away from the cognition of stress. In this way, the user frames the same SNS application differently (Vaast and Walsham 2005); rather than as a stressor, he or she cognitively frames as a 'distractor' 
that diverts him or her away from the stressful situation. SNS have a number of different features and functionalities which enable people to use them in different ways and to carry out many tasks, such as posting and sharing information, reacting to postings, reading friends' newsfeeds, communicating privately using a chat function, browsing through peoples' profiles, and searching for friends (Koroleva et al. 2011). Thus, SNS provide opportunities for diversion when an individual feels stressed by using them. If an SNS user experiences an SNS stress creating condition because of a particular way of using the SNS, his or her cognitive framing of the SNS is that of a stressor. He or she copes by switching to a different type of use on the same SNS to divert his or her attention from the stress. For example, a user might experience stress due to 'uncertainty' when he or she finds that the look of the landing or home page has changed. However, they can divert their attention by clicking on a friend's newsfeed and immersing themselves in that thread of information. Or, they might experience stress due to demands of 'social overload' and divert their attention by engaging in profile searching, switching to a chat feature or playing a game like Farmville or poker (Griffiths 2012). In this way, when faced with an SNS stressor, users have the possibility of coping by diverting themselves through different actions of use of the same SNS. That is, they may use the same SNS differently.

Thus, theoretically integrating the concepts of technology framing, cognitive representation and re-representation, and coping through distraction, we theorize that SNS users can divert their attention away from the stress experienced when using the SNS by doing something different within the same SNS application. That is, they engage in distraction through the use of the same SNS. Indeed, recent anecdotal evidence refers to SNS as "weapons of mass distraction" (McFedries 2013), where users engage in a continual stream of different actions on SNS (Dedyukhina 2018). The IS literatures on technostress, technology addiction, and coping as reported in the previous section, do not consider this phenomenon. Coping through distraction within the same SNS can be regarded as emotion focused coping because it 
involves cognitive re-representation (Beaudry and Pinsonneault 2005; Lazarus and Folkman 1984) of the same SNS.

We thus frame hypotheses 1 as:

\section{H1: SNS use stressors are positively associated with distraction within SNS.}

\subsubsection{Distraction through avoidance - outside the stress creating SNS}

In the second way of coping through distraction, individuals divert their attention by engaging in actions outside the stress causing SNS (Cooper et al. 2001; Lazarus 1966). For example, an SNS user who is stressed because he or she feels forced to disclose information in the SNS, perceives the stressor 'pattern'. This might lead to him or her to talk to family or friends, and use that particular SNS less frequently. Another example would be a situation in which a user is confronted with excessive social requests requiring action to help others. In such an example, the user perceives the stressor 'social overload', which might cause him or her to focus on other hobbies such as doing sports and thus use that SNS less. Alternatively, an individual might perceive the presence of SNS invasion and respond to that by switching to a different application such as an Internet browser, resulting in reduced use of that SNS. As shown by the above examples, the individual tries to get away from the stressful situation of SNS use by doing something different that does not entail the use of that SNS, such that their use of the SNS decreases. In the context of stressors from SNS use, it is known that individuals experiencing stress creating conditions may stop or reduce their usage (Maier et al. 2015a).

In the above ways of coping, we theorize that when faced with SNS stressors, individuals are likely to respond to the stressors by engaging in actions that divert their attention outside the stress causing SNS. Coping through distraction outside the SNS can be regarded as emotion 
focused coping because it involves avoiding the SNS altogether (Beaudry and Pinsonneault 2005; D'Arcy et al. 2014; Lazarus and Folkman 1984).

We thus frame hypotheses 2 as:

\section{H2: SNS use stressors are positively associated with distraction-outside-SNS}

\subsection{The moderating role of SNS Use Habit}

The stress literature informs us that the individual undertakes three key considerations in selection of a particular coping behavior - (1) the cognitive effort needed; (2) the control experienced; and (3) the risk faced - in executing the behavior (Lazarus 1966). The concept of 'habit' influences all these three factors, and is therefore an important factor for our study. Habit is defined as "learned sequences of acts that have become automatic responses to specific cues" (Verplanken and Aarts 1999, p. 104), or "a well-learned action sequence, originally intentional, that may be repeated as it was learned without conscious intention, when triggered by environmental cues" (de Guinea and Markus 2009, p. 437). The habit of a particular behavior implies high levels of automaticity and low levels of effort in executing the behavior (Ouellette and Wood 1998; Wood et al. 2002). When the individual selects coping behaviors that he or she is habituated with, actions according to those behaviors require less mental capacity, since doing something by habit does not require deliberation and thus is not likely to require much explicit effort (Verplanken and Orbell 2003). In contrast, non-habitual behavior is associated with lowered perceptions of control compared with habitual behavior (Wood et al. 2002). Finally, habituated behaviors are perceived as less risky because they are familiar (Chiu et al. 2012; Morrison and Firmstone 2000). These conditions are especially important under conditions of heavy mental load such as when facing stressors, when engaging in a habitual behavior would require less cognitive effort. Therefore habit is an important variable that influences the selection of a particular coping behavior. 
These arguments suggest that a particular coping behavior that is aligned with a specific habit has a stronger chance of emerging than one which is not (Verplanken and Orbell 2003). Given that our study examines distraction both within and outside the SNS, the individual's habit of using that SNS is an important factor for influencing the selection of these two as a coping strategy. Thus, we conceptually introduce habit of IT use as an important concept that influences coping with stress from feature rich IT.

Habits are well-learned sequences of actions that are repeated without conscious intention (de Guinea and Markus 2009). In the IS literature, the habit of using a particular IS predisposes individuals to greater use of that IS in an automatic way, implies less effort in using it, and prevents switching to a new system (Limayem and Hirt 2003; Polites and Karahanna 2012). If the user has a habit of using SNS, less effort is required to choose distraction through the use of the same SNS as a coping mechanism, than in the absence of the habit. The user automatically focuses on SNS use, and hence on the same system which causes stress, as a means of diversion. The high automaticity associated with habitual SNS use thus means that users are more predisposed toward coping with stressors from SNS use by looking to that same SNS to divert them (Diette et al. 2003; Traeger 2013), by using its different features or doing different tasks.

Thus, focusing on the relationship between SNS stressors and SNS distraction, we argue that stronger the user's SNS use habit, the higher the likelihood that he or she would keep using the same SNS as a means of diversion as a coping behavior in response to stressors from SNS use. That is, SNS use habit increases the probability that SNS distraction will emanate from SNS stressors; in other words it strengthens the relationship between stressors from SNS use and SNS distraction. We thus hypothesize: 


\section{H3: SNS use habit positively moderates the relationship between SNS stressors and SNS distraction such that the effect is stronger for users having a stronger habit for using SNS.}

In contrast, a weaker habit for the use of SNS implies that when such individuals experience stressors from the use of SNS, they find greater automaticity and experience lower effort in abandoning or avoiding the stress creating behavior, i.e. use of SNS, and in engaging in distraction behavior outside the use of that SNS. Indeed, if they were to continue using the SNS, they would expend greater effort, experience lower control and perceive greater risk in doing so, since it would go against their SNS use habit (Wood et al. 2002). Thus, focusing on the relationship between SNS stressors and non-SNS distraction, we see that the weaker the habit for SNS use, the greater the tendency to engage in diversion outside the SNS, thereby avoiding the use of that SNS altogether, as a coping behavior in response to stressors from SNS use. SNS users with a weaker habit for SNS use will thus have a higher likelihood of engaging in distraction behaviors not relating to the use of SNS. That is, a weaker habit for SNS use increases the probability of non-SNS distraction emanating from SNS stressors; in other words, it strengthens the positive relationship between stressors from SNS use and distraction outside the SNS.

We thus hypothesize:

\section{H4: SNS use habit negatively moderates the relationship between SNS stressors and non-SNS distraction such that that the effect is stronger for users having a weaker habit of using SNS.}

\subsection{Distraction and SNS Addiction}

If an SNS user experiences SNS stressors because of a particular way of using the SNS, his or her cognitive representation of the SNS is that of a stressor. Since SNS are feature rich, he or she can cope by switching to a different type of use on the same SNS to divert his or her 
attention from the stress, thus cognitively re-representing the SNS as a distractor. Based on this possibility, the user's cognitive representation of the feature rich IT can undergo repeated transformations (Vaast and Walsham 2005) from a stressor to distractor/stress reliever. To give an example, if the individual finds that reading through friends' social requests is a stressor because it creates social overload, he or she can switch to a different action such as chatting with another friend to divert his or her attention away from the posts. If at some point, chatting becomes a stressor if, for example, because the friend wishes to talk longer than what the individual wants, the individual again copes by doing something different, perhaps by browsing through profiles. This is amply aided by the plethora of functionalities and features afforded by SNS, the use of which can take the individual into different experiences such as keeping abreast with current events, staying aware of friends' lives and activities, taking part in discussions and sharing life experiences. This implies that the more the individual uses the SNS as a means of distraction, the more he or she does things that are different from those causing the stress and the more he or she is able to divert himself or herself from the stress creating conditions. He or she may thus keep browsing, posting, chatting, playing games, commenting, etc., within the same SNS application.

Such a scenario implies an immersive use situation in which the individual may find it difficult to get out of the feature rich environment of the SNS application. In order to distract themselves to cope with the stress experienced, they would engage in use that is characterized by heightened involvement, making it more likely for them to keep using alternate features and doing different things within the SNS. Indeed, it is known that the nature of the IT application is an important trigger for the nature of use (de Guinea and Markus 2009). For SNS there exist myriad different functionalities that can enable repeated changes in cognitive representation to keep using within the same application. It is thus possible to suggest that distraction through use of the same SNS may be associated with compulsive and excessive use such that individuals are behaviorally addicted to SNS use. The more the individuals 
adopts this coping strategy, the greater the likelihood of their addiction to the same stress creating SNS.

We thus frame hypotheses 3 as:

\section{H5: Distraction within SNS has a positive association with SNS addiction}

On the other hand, if the individual engages in coping through distraction outside the SNS, their attention is diverted away from the SNS altogether. They do things not related to the use of the SNS. The scenarios described above would not happen, so that there is no substantive reason to believe that they would be addicted to the use of the SNS. Indeed, the more they engage in coping through distraction outside the SNS, the less likely they are to be addicted to SNS use. Thus we anticipate a negative association of distraction outside SNS with SNS addiction.

\section{H6: Distraction outside SNS has a negative association with SNS addiction}

\section{METHODS}

The research model was empirically tested using data collected from three different surveys at three points in time over one year. The particular SNS we select is Facebook because it is the most prominent and general SNS application (Krasnova et al. 2015). The respondents were users of Facebook. For the purpose of anchoring our study, it is necessary to specify the particular SNS/feature rich IT - Facebook is the SNS/feature rich IT in our study. Thus all other applications are outside this feature rich $\mathrm{IT}^{5}$. We describe below the survey design, data collection, data analysis and results.

\footnotetext{
${ }^{5}$ For the sake of illustration, if we had considered an internet browser as the feature rich IT in our study then seeking solace within the internet browser (i.e. using any webpage such as news, reference reading etc.) would embody the top pathway. Seeking solace outside the internet browser (i.e. doing anything that does not involve the use of the internet browser) would embody the bottom pathway.
} 


\subsection{Survey Design}

The items for the model's constructs, described in the table of the Appendix C (Table 8), are as follows.

SNS stressors. The construct SNS stressors is conceptualized as a second-order reflective (Edwards 2001) latent construct with six first-order dimensions, also reflective. Specifically, we adapted items from prior SNS stress research (Maier et al. 2015a; 2015b). Accordingly, the first-order constructs are social overload $(\alpha=0.91)$, pattern $(\alpha=0.87)$, disclosure $(\alpha=0.82)$, uncertainty $(\alpha=0.90)$, complexity $(\alpha=0.90)$ and invasion $(\alpha=0.86)$.

We considered two bodies of literature therein. We examined the properties of reflective constructs as well as of the nature of stressors. There are four points to be noted in this regard (Jarvis et al. 2003). First, each first order constructs of a reflective second order construct represents a manifestation and can be viewed as one of its dimensions. Therefore the direction of causality is from the second order construct to its facets, the first order sub-constructs. In the case of SNS Stressors, this means that the stress from SNS use is manifested in any of the first order dimensions. This means that a user would experience stress from SNS use by experiencing any one of the first order SNS stressors. Second, the first order constructs are interchangeable as to their effects. That is, all first order constructs are equally valid facets of the second order construct. In our case, for example, it is not necessary that when a user is experiencing stress from SNS use, he or she has to experience all of the first order stressors just any one (or more) of them. Third, co-variation among the first order constructs is not unexpected, and fourth, the nomological networks associated with them are expected to be similar. We have no reason to believe, for instance, that any one of the first order constructs associated with SNS stressors would have a substantially different nomological network from any of the other first order constructs associated with it. These conditions are typical of 
reflective constructs (Edwards 2001; Jarvis et al. 2003) ${ }^{6}$. This representation is consistent with previous literature on stress that models role stressors as a reflective construct (Law et al. 1998), and with technostress literature that models technostress creating conditions both from general office IT applications (e.g. Ragu-Nathan et al 2008) and also from SNS use in particular (Maier et al. 2015b), as a second order reflective construct.

Distraction within SNS and Distraction outside SNS. The two distraction constructs were conceptually developed and empirically validated in this paper. As described and explained, distraction reflects the diversion of the individual's attention from the stress creating activity by engaging in a different activity (Duhachek 2005; Traeger 2013; Wrosch et al. 2011). We thus conceptualize distraction within the SNS as an individual's engagement in a different activity within the same feature rich IT application. Distraction outside SNS was conceptualized as engagement in a different activity outside the same feature rich IT application. We performed a scale development process for this construct that consists of multiple methodological steps, which we describe in detail in Appendix B.

SNS addiction. To measure SNS addiction, items were adapted from prior research discussing SNS addiction (Turel and Serenko 2012).

SNS use habit. The measure SNS use habit is based on general research discussing habit (Limayem et al. 2007) as well as on measures used to capture habit in the context of SNS (Turel and Serenko 2012).

\footnotetext{
${ }^{6}$ In formative second order latent constructs on the other hand, the direction of causality, or emanation of meaning, is from the first order dimensions to the second order construct. The first order measures compositely form the second order construct, such that the full meaning of the composite latent construct is derived collectively from all its measures. In IS research, firm performance, for example, has been modelled formatively as a second order formative construct composed of first order dimensions of operational excellence, revenue growth and customer service. The logic being that in order to capture a firm's performance, a consideration of all three is necessary, that is, all three contribute to performance such that the direction of causality is from the first order to the second order constructs (Rai et al. 2006).
} 
Control Variables. We include SNS use, age, gender and perceived enjoyment as control variables. Prior research indicates that these variables might influence IT addiction (Turel 2015). Age and gender were both measured with one single item that indicated the absolute value of the variable. For measuring SNS use, different actions which can be done using SNS were captured. These actions have been identified in prior research on SNS use (Koroleva et al. 2011) and we adapted them to the context of using Facebook. These include among others an active participation ("I participated in Facebook actively by posting and sharing thoughts, feelings, and impressions"), passive following ("I participated in Facebook passively by following news and reading the newsfeed"), social browsing ("I used Facebook to browse the profiles of friends or other users"), social searching ("I used Facebook to search for people and send friendship requests"), or private communication ("I used Facebook to communicate (e.g., chat, private messages) with friends"). Finally, perceived enjoyment was measured as suggested by Turel and Serenko (2012)

\subsection{Data Collection}

To evaluate the research model we set up a three-wave survey panel. In this panel, the constructs - Social overload, Pattern, Disclosure, Uncertainty, Complexity, Invasion, SNS distraction within / outside the SNS, SNS use habit, SNS use, SNS enjoyment and SNS addiction - were captured at three different points in times using three surveys over one year. We measured Social overload, Pattern, Disclosure, Uncertainty, Complexity and Invasion in the first survey (time $\mathrm{t}=1$ ), SNS distraction within / outside the SNS, SNS use habit in the second survey $(\mathrm{t}=2)$, and SNS addiction in the third survey $(\mathrm{t}=3)$. This design enabled us to reduce the likelihood of common methods bias in our data by temporally separating the measurement of different constructs (Podsakoff et al. 2003).

We have developed a database of individuals who have voluntarily expressed interest in and have agreed to be contacted for participating in research studies. For this study, we selected 
those who described themselves as users of Facebook, who were 695 in number. We used them as the initial list of potential participants for our study on the influence of SNS stress on SNS addiction. All individuals were from a European Union country classified in the United Nations as 'developed'. We sent them an email, requesting them to complete the first round of surveys. We also sent one email reminder. Each email and email reminder included a unique link to our first survey, so that we could ensure that each participant completed the survey only once. 531 individuals completed the first survey. We re-contacted each individual who had completed the first survey round and asked them six months later to complete the second round of surveys. The email again included a unique link to our survey and the request to log in with their email-address. We reminded participants who did not complete the survey after the first email by sending another email. In this round, 498 individuals completed the second survey. We repeated this approach six months later, contacting the participants of previous surveys via email and asking them whether they would participate in the survey. As in the previous surveys, we made use of one email reminder. In the end, 444 Facebook users participated in all three rounds of surveys and completed the surveys. The demographic characteristics of the participants are included in Table 1. Individuals who participated in all surveys were offered the chance to enter a raffle for an iPad mini 4

\begin{tabular}{|c|c|c|c|c|c|c|c|c|}
\hline \multicolumn{9}{|c|}{ Gender: female (55/1\%); male (44.9\%) } \\
\hline \multirow{6}{*}{$\begin{array}{c}\text { Age } \\
\text { (mean } \\
35.81 \text { ) }\end{array}$} & $<20$ & 7.2 & \multirow{6}{*}{$\begin{array}{l}\text { Number of } \\
\text { friends in } \\
\text { SNS } \\
\text { (mean } \\
365 \text { ) }\end{array}$} & $<100$ & 8.6 & \multirow{6}{*}{$\begin{array}{c}\text { Time } \\
\text { spent on } \\
\text { Facebook } \\
\text { per day in } \\
\text { minutes } \\
\text { (mean } \\
64.5 \text { ) }\end{array}$} & $<15$ & 27 \\
\hline & $20-29$ & 26.8 & & $100-199$ & 13.7 & & $15-30$ & 27 \\
\hline & $30-39$ & 32.9 & & $200-299$ & 19.3 & & $31-45$ & 13 \\
\hline & $40-49$ & 18.4 & & 300-399 & 24.3 & & $46-60$ & 12 \\
\hline & $50-59$ & 13.1 & & $400-499$ & 21.6 & & $60-120$ & 10 \\
\hline & $60-70$ & 1.6 & & $>499$ & 12.5 & & $>120$ & 9.9 \\
\hline
\end{tabular}

Table 1: Demographics (these data are collected in the first survey at time $t=1$ )

\subsection{Sample Characteristics}

We did a number of checks to evaluate the characteristics of our sample. First we evaluated the representativeness of the sample from three aspects - age, gender and time spent using 
Facebook. The details are reported in Appendix E. Second, we tested for possible differences in the samples for the three waves. That is, we checked whether our final sample of 444 individuals was different to those who were invited (695 individuals), those who participated in the first wave (531 individuals) or those who participated in the first two waves (498 individuals). We compared these samples along the demographics from Table 1, that is, age, gender, number of friends and time spent on Facebook. We used the t-test and found that there were no significant $(\mathrm{p}>0.05)$ differences between our data sample and the other data samples. Third, we tested for non-response bias of the final sample of 444 by comparing the above-mentioned sample demographics with those who were invited, but did not participate. Additionally, for the final sample of 444 we compared the same sample demographics for the first and the last $33 \%$ and the first and the last $50 \%$ of the respondents. Using a t-test we saw no significant differences in either set of comparisons. Thus we deemed non-response bias not to be an issue. Finally, we tested for common method bias, as described in Appendix D. The tests show a very low probability for the presence of common methods bias affecting the relationships examined in the research model.

\subsection{Research Model Results}

We next test the research hypotheses through a structural equation model using partial least squares (PLS) method and SmartPLS 3.2.5 (Ringle et al. 2014). We use PLS-SEM because it is deemed suitable for investigating new theoretical relationships given its higher statistical power (Sarstedt and Mooi 2019). This is the case for our study because we conceptualize the phenomenon of distraction as a coping mechanism, develop the two new constructs of distraction within SNS and distraction outside SNS, and hypothesize new relationships involving them. PLS-SEM is also more amenable to modeling moderating relationships. In particular, we used Consistent PLS (PLSc). It provides a correction for possible overestimates of path coefficients, inter-construct correlations and indictor loadings, for reflective 
constructs. In general, studies suggest that the biases that might be present in PLSc estimates are comparable to that of covariance-based SEM (Dijkstra and Henseler 2015).

\subsubsection{Measurement model}

As the constructs used in the research model were modeled reflective, we assessed construct validity as follows (Bagozzi 1979). The mean and variance of each construct is shown in Appendix C. For each construct, the indicator reliability indicates the rate of the variance of an indicator that comes from the latent variables. To explain at least $50 \%$ of the variance of a latent variable by the indicators, each value must be 0.707 or greater (Carmines and Zeller 2008). This condition was fulfilled (see Table 8). In addition, all loadings have a significance level of at least 0.001 and hence are highly significant. This was tested by bootstrapping with 500 and 5,000 samples. We next used the measures of Composite Reliability (CR) and Average Variance Extracted (AVE) to determine construct reliability (Fornell and Larcker 1981). CR should be higher than 0.7 and AVE higher than 0.5. As Table 2 shows, both criteria are fulfilled. Next, discriminant validity describes the extent to which measurement items differ from one another (Campbell and Pisterman 1996). For appropriate discriminant validity, the square root of AVE (diagonal values in Table 2) should be greater than the corresponding construct correlations (Fornell and Larcker 1981), which was the case for our data as shown in Table 2. As the heterotrait-monotrait (HTMT) ratio of correlations criterion detects a lack of discriminant validity more reliably than the Fornell-Larcker criterion, it is also used to assess discriminant validity (Henseler et al. 2014). Using the absolute $\mathrm{HTMT}_{0.85}$ criterion indicates that the constructs exhibit good discriminant validity, because the highest correlations between two constructs is lower than 0.85 (as we use $\mathrm{HTMT}_{0.85}$ ) and the bootstrapping approach indicates that the upper confidence interval limit is below 1 . This means that the HTMT inference criterion indicates that all HTMT values are significantly different from 1 and discriminant validity has been established. Finally, we also checked for variance inflation factor (VIF) and results reveal that each VIF is lower than the 
recommended value of 5 (Rogerson 2015). Thus, multi-collinearity was not found to be a substantive issue.

\begin{tabular}{|c|c|c|c|c|c|c|c|c|c|c|c|c|c|c|c|c|c|c|}
\hline & & C. $\alpha$ & CR & AVE & 1 & 2 & 3 & 4 & 5 & 6 & 7 & 8 & 9 & 10 & 11 & 12 & 13 & 14 \\
\hline 1 & Social overload & 0.911 & 0.931 & 0.694 & 0.83 & & & & & & & & & & & & & \\
\hline 2 & Pattern & 0.868 & 0.916 & 0.784 & 0.49 & 0.89 & & & & & & & & & & & & \\
\hline 3 & Invasion & 0.864 & 0.917 & 0.786 & 0.33 & 0.06 & 0.89 & & & & & & & & & & & \\
\hline 4 & Disclosure & 0.823 & 0.877 & 0.643 & 0.24 & 0.40 & 0.08 & 0.80 & & & & & & & & & & \\
\hline 5 & Complexity & 0.901 & 0.930 & 0.768 & 0.23 & 0.40 & -0.14 & 0.31 & 0.88 & & & & & & & & & \\
\hline 6 & Uncertainty & 0.901 & 0.938 & 0.834 & 0.15 & 0.14 & 0.12 & 0.31 & 0.22 & 0.91 & & & & & & & & \\
\hline 7 & $\begin{array}{l}\text { Distraction } \\
\text { within SNS }\end{array}$ & 0.951 & 0.963 & 0.837 & 0.18 & 0.09 & 0.24 & 0.03 & -0.04 & 0.03 & 0.92 & & & & & & & \\
\hline 8 & $\begin{array}{l}\text { Distraction } \\
\text { outside SNS }\end{array}$ & 0.907 & 0.935 & 0.781 & 0.06 & 0.10 & -0.03 & 0.13 & 0.09 & 0.19 & -0.05 & 0.88 & & & & & & \\
\hline 9 & SNS addiction & 0.911 & 0.933 & 0.736 & 0.30 & 0.23 & 0.28 & 0.14 & 0.09 & 0.11 & 0.36 & -0.08 & 0.86 & & & & & \\
\hline 10 & $\begin{array}{l}\text { Perceived } \\
\text { enjoyment }\end{array}$ & 0.957 & 0.984 & 0.926 & 0.17 & 0.10 & 0.29 & 0.05 & -0.08 & 0.13 & 0.66 & -0.01 & 0.36 & 0.96 & & & & \\
\hline 11 & SNS use habit & 0.910 & 0.938 & 0.791 & 0.18 & -0.13 & 0.63 & -0.08 & -0.35 & 0.02 & 0.16 & -0.05 & 0.18 & 0.22 & 0.89 & & & \\
\hline 12 & SNS use & 0.852 & 0.890 & 0.574 & -0.06 & -0.12 & 0.08 & -0.22 & -0.21 & -0.15 & 0.19 & -0.13 & 0.41 & 0.21 & 0.18 & 0.76 & & \\
\hline 13 & Age & 1.000 & 1.000 & 1.000 & 0.04 & 0.06 & 0.04 & 0.05 & 0.09 & -0.01 & 0.07 & 0.03 & 0.08 & 0.05 & 0.04 & 0.01 & 1.00 & \\
\hline 14 & Gender & 1.000 & 1.000 & 1.000 & 0.00 & 0.01 & -0.05 & 0.04 & 0.05 & -0.02 & -0.04 & 0.03 & -0.09 & -0.04 & 0.01 & 0.01 & -0.11 & 1.00 \\
\hline
\end{tabular}

Table 2: Average Variance Extracted (AVE), Composite Reliability (CR), Cronbach Alpha (C. a), and Bivariate Correlations

Note 1: Square root of AVE is contained on the diagonal

\subsubsection{Structural model}

We made use of the coefficient of determination $\left(\mathrm{R}^{2}\right)$ as well as the significance levels of each path coefficient to evaluate the structural model. Figure 2 indicates that SNS stressors have a significant positive influence on distraction within SNS (H1 supported) and a significant positive influence on distraction outside SNS (H2 supported). We also see that SNS use habit moderates the relationship between SNS stressor and distraction within SNS positively (H3 supported). It moderates the relationships between SNS stressor and distraction outside SNS negatively (H4 supported). Results also indicate that distraction within SNS is positively associated with SNS addiction (H5 supported), while distraction outside SNS has no significant association with SNS addiction (H6 not supported) ${ }^{7}$.

With respect to $\mathrm{R}^{2}$, a variance of 19.7 percent is explained for distraction within SNS and 9.8 percent is explained for distraction outside SNS. 27.6 percent of the variance of SNS addiction is explained in our research model. The two control variables, age and gender, have

\footnotetext{
${ }^{7}$ We analysed our research model with a formative second order specification for SNS Stressors. We did not find any substantive change in the model.
} 
no significant influence on SNS addiction, while SNS use and perceived enjoyment have a significant positive effect (see Figure 2).

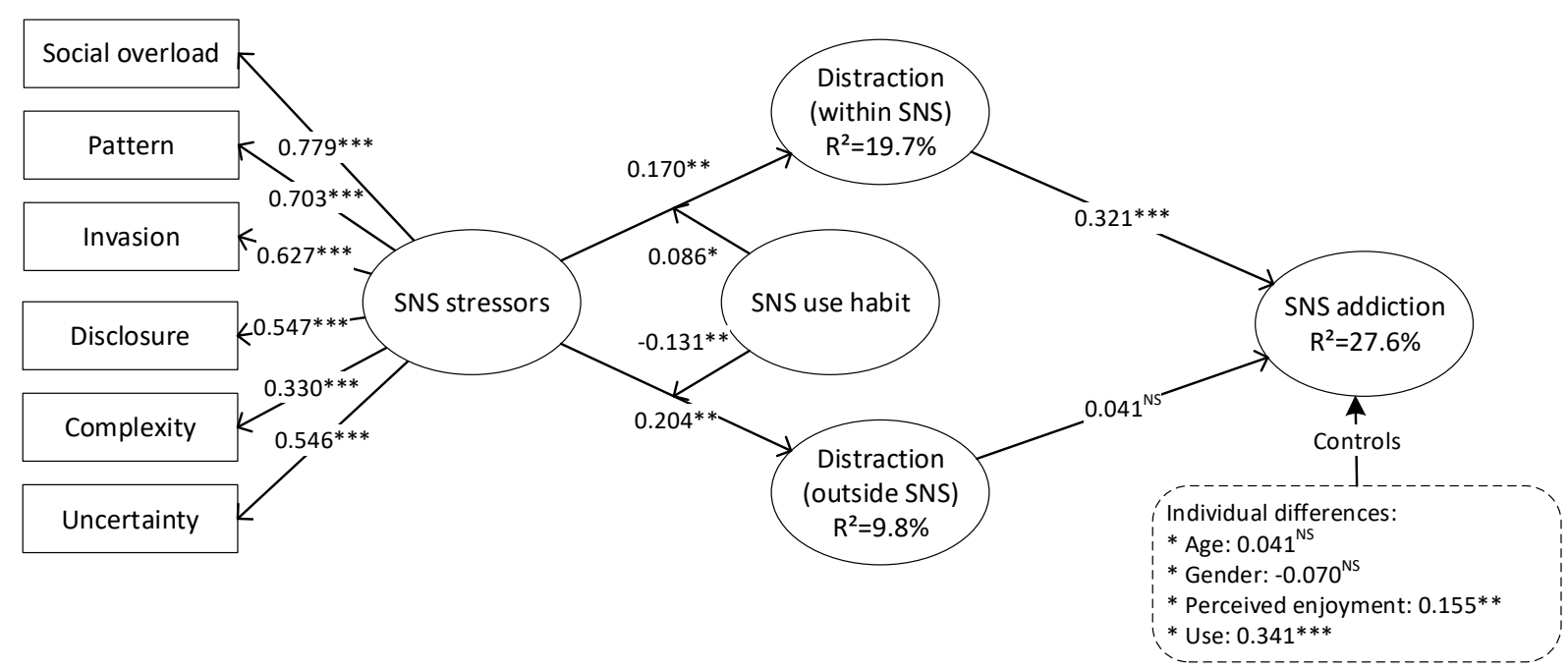

Figure 2: Research results based on three surveys Note 1: $* \mathbf{p}<0.05 ; * * \mathbf{p}<0.01 ; * * * \mathbf{p}<0.001$; otherwise NS (non-significant)

Note 2: SNS Stressors measured at $t=1$, Distraction (within SNS) and Distraction (outside SNS) measured at $t=2$ and SNS addiction measured at $\mathrm{t}=3$

\subsection{Further Analysis}

We tested for potential reverse relationships in our research model in the following way. First we tested for the relationship between both Distraction within SNS (measured at $t=1$ ) and Distraction outside SNS (measured at $\mathrm{t}=1$ ), and SNS stressors (measured at $\mathrm{t}=2$ ). The results were: Distraction within SNS and SNS stressors $(\beta=0.095 ; \mathrm{p}>0.05)$ and Distraction outside SNS and SNS stressors $(\beta=-0.019 ; p>0.05)$. Thus these relationships were not significant. Next we tested for the relationship between SNS addiction (measured at $\mathrm{t}=2$ ), and Distraction within SNS (measured at $\mathrm{t}=3$ ) and Distraction outside SNS (measured at $\mathrm{t}=3$ ). The results were: SNS addiction and Distraction within SNS $(\beta=0.089 ; \mathrm{p}>0.05)$ and SNS addiction and Distraction outside SNS ( $\beta=-0.047 ; p>0.05)$. Thus these relationships were not significant. Taken together these tests show that reverse relationships is not a significant concern.

\subsection{Limitations}

As with all research, that reported here is limited in some ways. First, the time between the three surveys was based on convenience and practicality of data collection. We selected six 
weeks as the time interval between each successive survey. However we cannot say for sure that the results would not have been different had the time interval not been the same or had the successive intervals not been equal. Second, the number of 'friends' for a given respondent might have changed between the first, second and third surveys. The research model does not take this into account. Third, we focused on the voluntary use of Facebook. Although the arguments developed and validated are not particular to Facebook, the results are subject to the boundary conditions of voluntary and non-work use of SNS.

\section{DISCUSSION AND IMPLICATIONS}

Drawing from the IS and psychology literatures, the paper develops and validates a new theoretical explanation for the phenomenon of why and how individuals who experience stressful conditions from the use of SNS can be addicted to the same SNS. In so doing, it theoretically introduces and empirically validates the concept of distraction as a coping behavior to deal with the stress creating effects of use of SNS. We next explain the paper's contributions, and its implications for practice and policy.

\subsection{Contributions to Literature}

This paper theoretically develops and empirically validates a set of relationships that explain how users cope with technostress they experience from use of SNS applications, through distraction. Such distraction can occur through two pathways - (a) through use of the same SNS that causes the stress and (b) through other means outside of the use of the SNS. Our first theoretical contribution is thus to introduce to the IS literature, distraction as a coping behavior in response to the stressors experienced from use of SNS. This is a new conceptual development because it introduces a new kind of coping behavior that adds theoretically to our understanding of how individuals cope with technostress. We conceptually define the two kinds of distraction, develop the scales for the associated constructs, and provide their 
empirical validity. These constructs can be adapted by future research examining other phenomenon relating SNS.

As a second contribution, we establish a theoretical link between stressors from use of SNS and addiction to the same SNS. According to the literature, stressors from use of SNS are associated with its reduced use (Maier et al. 2015b). We show that through the coping path of distraction within SNS, these stressors can also be associated with addiction. Such a link is not explained by traditional models of technology use. This gives us novel theoretical insight regarding the possibility of both stressors and addiction vis-à-vis the same SNS being present along with the other. Recent research commentaries (Lyytinen and Yoo 2002) have noted that feature rich IT can spawn new phenomenon that need to be understood. Our results speak to this by providing a possible theoretical link between SNS stressors and SNS addiction that challenges the existing conceptual separateness of these two phenomena, which have thus far been studied separately. To our knowledge this is the first paper to develop and explain a conceptual linkage between these two concepts. We note that in the coping path of distraction outside the SNS we did not find support for an association from stress from SNS stressors to SNS addiction, because the user gets away from the SNS.

Third, we show habit for use of SNS as a factor that explains why the individual chooses between the two pathways. A strong habit increases the possibility of the pathway that includes distraction using the same SNS, and a weak habit that of the pathway that includes distraction outside the SNS. Further, on the former pathway, the positive moderation of habit on the relationship between SNS stressors and distraction using the same SNS, contributes to the strengthening of the relationship between stress from SNS use and SNS addiction. This effect of IT use habit we observe in our study is more complex and nuanced than the traditional understanding of habit, which regards it in a more straightforward manner, as a factor that increases use of existing IT and prevents adoption of new systems. 
We also contribute in a cross-disciplinary manner (Tarafdar and Davison 2018) to the psychology literature. Traditionally, distraction as a coping behavior that implies diverting attention by doing something which is completely unconnected to the stress creating environment (Cooper et al. 2001; Landsbergis 1988). This is the distraction outside SNS pathway in our study. However, as evidenced by support for H1, there exists a second, theoretically novel pathway of distraction by using the same SNS. This pathway entails diverting attention through different kinds of use of the same SNS; therefore it does not let the user get away from the stress causing SNS application, because the same SNS application provides multiple options for diversion. In this pathway, the individual thus embeds himself or herself in the same technology environment that is causing stress, instead of getting away from it completely. This forms a theoretical contribution to the psychology literature by highlighting a novel aspect of coping through distraction.

The boundary conditions of our theorizing and empirical findings include the individual's use of SNS in a non-organizational context. However, relationships we examine can be conceptually extended to other feature rich IT applications and feature rich IT devices such as smartphones, tablets and PC's. Given that feature rich applications and devices are an essential part of modern computing and societal milieus, future research can extend the relationships we examine across a range of devices and applications. For example, an individual could experience stress from an email application, within a feature rich IT device such as a PC. They could potentially cope by distracting themselves through another application (e.g. a web browser) on the same feature rich IT device, the PC. Such a scenario can lead to deviant work behaviors such as cyber-loafing (Aghaz and Sheikh 2016). Future research can explore potential links between this phenomenon and the one we examine in this paper. Finally, we considered one moderating factor, the habit of SNS use. There can be others such as social or peer pressure. There can also be other potential explanations for the 
link between SNS stressors and SNS addiction such as the benefit versus cost of using SNS.

We suggest these as avenues for future research.

\subsection{Implications for Practice and Policy}

Our study has implications for individuals who use feature rich IT such as SNS, for providers of such applications, and for regulators and policy makers who are trying to constructively shape the societal milieu in which such IT is used.

Firstly, more and more individuals habitually use feature rich IT applications such as SNS. As demonstrated in this study, there is the possibility of getting caught up in the distraction using the same SNS pathway and of failing prey to addiction. By highlighting this pathway that can cause the link between SNS related stress and SNS addiction, our findings serve, at the very least, for users of SNS to be mindful of the possibility of such behaviors.

Secondly, providers of SNS applications want to increase the features and functionality of these applications to enable different kinds of use. A potential consequence is the possibility of addiction to SNS, even as users are stressed. This points to an ambivalent and potentially murky aspect of continually developing and evolving SNS to provide greater functionality. It is also a timely and helpful reminder for SNS providers whose revenue models depend heavily on how much time users spend on their websites and who, in the current environment are struggling to retain the trust of users and regulators because there is increasing social clamor and commentary around addiction to SNS like Facebook and Instagram ${ }^{8}$. Technology companies are beginning to take heed ${ }^{9}$. They could find our results helpful in focusing their efforts.

\footnotetext{
${ }^{8}$ See for example, https://www.theguardian.com/technology/2018/may/08/social-media-copies-gamblingmethods-to-create-psychological-cravings and https://www.huffingtonpost.co.uk/anastasia-dedyukhina/homodistractus-how-the-m b 16762592.html

${ }^{9}$ See for example, https://www.theguardian.com/technology/2018/may/08/google-digital-wellbeing-tools-techaddiction and https://www.ft.com/content/24eeaed6-8a7f-11e8-b18d-0181731a0340
} 
Thirdly, from a societal and policy perspective, there are implications for possible regulations around the design of SNS applications as well as the education of users around behavioral patterns of use. The two types of distraction behaviors we highlight in this paper can be a basis for inputs to potential government policy initiatives ${ }^{10}$ focused on helping individuals to navigate commonly used applications such as SNS, and on framing regulation for technology providers to make users aware of the possible risks of using the technologies they design.

\subsection{Conclusion}

The use of feature rich IT such as SNS is now ubiquitous. Even though individuals experience stressors from their use, they may find themselves unable to stop using them. In this paper, we develop and validate a new theoretical explanation for a possible relationship between stress from and addiction to SNS. As IS research delves into the growing scholarly discourse on the dark side of IT use, technostress and technology addiction have emerged as two distinct theoretical streams. This paper contributes to this discourse by theorizing and empirically validating a potential link between the two streams.

\footnotetext{
${ }^{10}$ See for example, https://www.gov.uk/government/consultations/online-harms-white-paper/online-harmswhite-paper.
} 
Appendix A: IS literature on coping

\begin{tabular}{|c|c|c|}
\hline Study & Research Method & Coping behaviors \\
\hline \multicolumn{3}{|c|}{ Coping with stress from implementation of new IS } \\
\hline $\begin{array}{l}\text { Beaudry and } \\
\text { Pinsonneault } \\
2005\end{array}$ & $\begin{array}{c}\text { Interviews } \\
\text { Organizational }\end{array}$ & $\begin{array}{l}\text { Benefits satisficing and self-preservation (Emotion } \\
\text { focused), } \\
\text { Benefits maximizing (Problem focused), } \\
\text { Disturbance handling } \\
\text { (Mix of problem and emption focused) }\end{array}$ \\
\hline $\begin{array}{l}\text { Beaudry and } \\
\text { Pinsonneault } \\
2010\end{array}$ & $\begin{array}{c}\text { Survey } \\
\text { Organizational }\end{array}$ & $\begin{array}{l}\text { Venting, distancing (Emotion focused) } \\
\text { Seeking social support, task adaptation, seeking } \\
\text { instrumental support (Problem focused) }\end{array}$ \\
\hline $\begin{array}{l}\text { Stein et al. } \\
2015\end{array}$ & $\begin{array}{l}\text { Interviews } \\
\text { Organizational }\end{array}$ & $\begin{array}{l}\text { Venting (Emotion focused) } \\
\text { Adaptation, seeking instrumental support (Problem } \\
\text { focused) }\end{array}$ \\
\hline $\begin{array}{l}\text { de Guinea } \\
\text { and Webster } \\
2013\end{array}$ & $\begin{array}{c}\text { Experience } \\
\text { sampling study \& } \\
\text { experiment } \\
\text { Non-organizational } \\
\end{array}$ & $\begin{array}{l}\text { Exploitive, adaptive behaviors } \\
\text { (Problem focused) }\end{array}$ \\
\hline $\begin{array}{l}\text { Bala and } \\
\text { Venkatesh } \\
2015\end{array}$ & $\begin{array}{c}\text { Survey } \\
\text { Organizational }\end{array}$ & $\begin{array}{l}\text { Avoidance (Emotion focused) } \\
\text { Exploitation, exploration-to-innovate, exploration-to- } \\
\text { revert (Problem focused) }\end{array}$ \\
\hline \multicolumn{3}{|c|}{ Coping with technostress, that is from ongoing use of IS } \\
\hline $\begin{array}{l}\text { D'Arcy et al. } \\
2014\end{array}$ & $\begin{array}{c}\text { Survey } \\
\text { Organizational }\end{array}$ & $\begin{array}{l}\text { Moral disengagement and avoidance of IS use } \\
\text { requirements } \\
\text { (Emotion focused) }\end{array}$ \\
\hline $\begin{array}{l}\text { Galluch et } \\
\text { al. } 2015\end{array}$ & $\begin{array}{l}\text { Experiment } \\
\text { Organizational }\end{array}$ & $\begin{array}{l}\text { Method control, resource control } \\
\text { (Problem focused) }\end{array}$ \\
\hline $\begin{array}{l}\text { Maier et al. } \\
2015 b\end{array}$ & $\begin{array}{c}\text { Survey \& } \\
\text { experiment } \\
\text { Non-organizational }\end{array}$ & Avoiding use of IS (Emotion focused) \\
\hline
\end{tabular}

Table 3: Review of IS literature on the individual's coping behaviors

\section{Appendix B: Scale development for distraction within and outside SNS}

In this section, we provide methodological details about steps undertaken for the development and validation of the scales for the distraction within and outside SNS constructs. In conceptualizing and validating these constructs we followed guidelines provided in the literature (Polites et al. 2012). We note that the scale development and validation were done with data collected at time $t=1$. This was a different (holdout) data sample than the one that was used for hypothesis testing, which was collected at time $t=2$. The use of separate samples for scale development/validation, and for hypothesis testing, is regarded as an appropriate and desirable methodological step (e.g. Ragu-Nathan et al. 2008).

\section{Step 1: Item development and initial face validity}


We conceptualize the distraction within SNS and outside SNS starting with identification of related concepts in previous research (Duhachek 2005; Traeger 2013; Wrosch et al. 2011), we first developed a pool of initial items that matched the definitions. To assess the initial face validity of the items, we discussed them with three experienced researchers in technostress and technology addiction. After modifying the items as suggested in these discussions, we interviewed seven SNS users. In these interviews, participants rated the relevance and clarity of each item, resulting in a final pool of items. Three items were thus further revised based on these discussions to ensure high content validity. These steps follow methods used in recent research developing new scales (Chin et al. 1997; Ragu-Nathan et al. 2008; Salisbury et al. 2002). A total of five items were obtained for each distraction within SNS and four items for distraction outside SNS.

\section{Step 2: Q-sort for assessment of content validity}

In a next step, we assessed the content validity of the new items by undertaking the Q-sort procedure as suggested in prior research (Landis and Koch 1977; Nahm et al. 2002). We asked 44 individuals to assign each newly developed item to one of the two new first order constructs, namely, distraction within SNS and distraction outside SNS, or to one named 'others' if the item did not fit distraction within SNS and distraction outside SNS. A third option to mark that it was not possible to assign the item to any of these constructs was also provided. First we presented and defined the two constructs - distraction within SNS and distraction outside SNS - to each participant. We next provided them with all items. Then, each participant read each item and assigned it to one of the three possibilities. Based on all 44 responses, we calculated three ratios for each item - (1) matching with the correct construct (i.e. an item for distraction within SNS was matched with distraction within SNS), (2) matching with the other distraction construct (i.e. an item for distraction within SNS was matched with distraction outside SNS), and (3) matching with none of the constructs (i.e. an item for distraction within SNS or distraction outside SNS was matched with neither). As suggested in prior research (Landis and Koch 1977; Nahm et al. 2002), we rejected all items which were assigned correctly by less than 61 percent. The results are summarized in Error! Reference source not found.. Since all the items were correctly matched at $61 \%$ or above, no item was removed. In summary, this reveals that the items are semantically coherent.

\begin{tabular}{|c|c|c|c|c|}
\hline Construct & Label & $\begin{array}{c}\text { Distraction } \\
\text { within SNS }\end{array}$ & $\begin{array}{c}\text { Distraction } \\
\text { outside SNS }\end{array}$ & Others \\
\hline \multirow{4}{*}{$\begin{array}{c}\text { Distraction within } \\
\text { SNS }\end{array}$} & DisSNS-1 & $88.6 \%$ & $6.8 \%$ & $4.6 \%$ \\
\cline { 2 - 5 } & DisSNS-2 & $95.5 \%$ & $2.3 \%$ & $2.3 \%$ \\
\cline { 2 - 5 } & DisSNS-3 & $97.7 \%$ & $2.3 \%$ & $0.0 \%$ \\
\cline { 2 - 5 } & DisSNS-4 & $95.5 \%$ & $4.6 \%$ & $0.0 \%$ \\
\cline { 2 - 5 } & DisSNS-5 & $90.9 \%$ & $4.6 \%$ & $4.6 \%$ \\
\hline \multirow{3}{*}{$\begin{array}{c}\text { Distraction } \\
\text { outside SNS }\end{array}$} & DisNoSNS-1 & $0.0 \%$ & $97.7 \%$ & $2.3 \%$ \\
\cline { 2 - 5 } & DisNoSNS-2 & $0.0 \%$ & $95.5 \%$ & $4.6 \%$ \\
\cline { 2 - 5 } & DisNoSNS-3 & $9.1 \%$ & $88.6 \%$ & $2.3 \%$ \\
\cline { 2 - 5 } & DisNoSNS-4 & $6.8 \%$ & $84.1 \%$ & $9.1 \%$ \\
\hline
\end{tabular}

Table 4: Q-sort for assessment of content validity; values in percentage

\section{Step 3: Exploratory and confirmatory factor analysis for assessment of convergent and} discriminant validity. We collected data for the items developed in Step 2, at time $\mathrm{t}=1$ (first survey). This data was used as a holdout sample to perform tests for exploratory and confirmatory factor analysis, reliability, and convergent, divergent and second-order validities, using SPSS 23.0. Results of exploratory analysis reveal two factors - distraction within SNS and distraction outside SNS. As shown in Table 5, each item has satisfactory 
loadings, that is, $>0.70$ on its respective construct and $<0.45$ on the other construct. As a result, no item was removed. Confirmatory factor analysis results are shown in Table 6 . There were no significant correlations among any of the error terms for distraction within SNS and distraction outside SNS. The combined exploratory and confirmatory factor analysis illustrated convergent and discriminant validity of these two constructs.

\begin{tabular}{|c|c|c|c|}
\hline Construct & Label & $\begin{array}{c}\text { Distraction } \\
\text { within SNS }\end{array}$ & $\begin{array}{c}\text { Distraction } \\
\text { outside SNS }\end{array}$ \\
\hline \multirow{4}{*}{ Distraction within SNS } & DisSNS-1 & 0.869 & 0.017 \\
\cline { 2 - 4 } & DisSNS-2 & 0.929 & -0.047 \\
\cline { 2 - 4 } & DisSNS-3 & 0.944 & -0.026 \\
\cline { 2 - 4 } & DisSNS-4 & 0.930 & 0.007 \\
\cline { 2 - 4 } & DisSNS-5 & 0.875 & -0.029 \\
\hline \multirow{3}{*}{$\begin{array}{c}\text { Distraction outside } \\
\text { SNS }\end{array}$} & DisNoSNS-1 & 0.102 & 0.717 \\
\cline { 2 - 4 } & DisNoSNS-2 & 0.002 & 0.870 \\
\cline { 2 - 4 } & DisNoSNS-3 & -0.103 & 0.856 \\
\cline { 2 - 4 } & DisNoSNS-4 & -0.080 & 0.884 \\
\hline \multicolumn{2}{|c|}{ Eigenvalues } & 4.185 & 2.771 \\
\hline
\end{tabular}

Notes:

Extraction method: principal component analysis.

Rotation method: Varimax with Kaiser normalization.

Rotation converged in three iterations.

Table 5: Results of Exploratory Factor Analysis- Rotated component matrix of diversion within and outside SNS

\begin{tabular}{|c|c|c|c|}
\hline \multirow{2}{*}{ Construct } & Label & $\begin{array}{c}\text { Distraction within } \\
\text { SNS }\end{array}$ & $\begin{array}{c}\text { Distraction outside } \\
\text { SNS }\end{array}$ \\
\hline \multirow{4}{*}{$\begin{array}{c}\text { Distraction within } \\
\text { SNS }\end{array}$} & DisSNS-1 & 0.869 & \\
\cline { 2 - 4 } & DisSNS-2 & 0.929 & \\
\cline { 2 - 4 } & DisSNS-3 & 0.944 & \\
\cline { 2 - 4 } & DisSNS-4 & 0.930 & \\
\cline { 2 - 4 } & DisSNS-5 & 0.875 & 0.717 \\
\hline \multirow{3}{*}{$\begin{array}{c}\text { Distraction } \\
\text { outside SNS }\end{array}$} & DisNoSNS-1 & & 0.870 \\
\cline { 2 - 4 } & DisNoSNS-2 & & 0.856 \\
\cline { 2 - 4 } & DisNoSNS-3 & & \\
\cline { 2 - 4 } & DisNoSNS-4 & \multicolumn{2}{|l}{} \\
\hline Note: Factor loadings lower than .45 are not shown & \\
\hline
\end{tabular}

Table 6: Results of confirmatory factor analysis

\section{Step 4: Construct reliability}

Following satisfactory results from the exploratory and confirmatory factor analysis we next provide means, standard deviation, and reliability of the two constructs, distraction within SNS and distraction outside SNS in Table 7. For each scale, Cronbach's alpha values were greater than the recommended minimal threshold of 0.7 (Hair 1995; Nunnally and Bernstein 1994;).

\begin{tabular}{|l|c|c|c|}
\hline Construct & Mean & Standard deviation & Reliability \\
\hline Distraction within SNS & 4.11 & 1.54 & 0.91 \\
\hline
\end{tabular}


Distraction outside SNS

2.61

1.15

0.89

Table 7. Mean, standard deviation, and alpha-reliability of distraction within SNS and distraction outside SNS

\section{Appendix C: Construct Items}

The items for the study's constructs as well as the corresponding loadings are presented below.

\begin{tabular}{|c|c|c|}
\hline Construct & Item & Loading \\
\hline \multicolumn{3}{|c|}{ SNS stressors } \\
\hline \multicolumn{3}{|c|}{ Please respond to each of the following statements } \\
\hline \multicolumn{3}{|c|}{ Social overload (Mean: 3.74; Standard Deviation: 1.21) } \\
\hline SO-1 & $\begin{array}{l}\text { I take too much care of my friends' well being on } \\
\text { Facebook. }\end{array}$ & 0.894 \\
\hline $\mathrm{SO}-2$ & I deal with my friends' problems too much on Facebook. & 0.900 \\
\hline SO-3 & $\begin{array}{l}\text { My sense of being responsible for how much fun my } \\
\text { friends have on Facebook is too strong. }\end{array}$ & 0.832 \\
\hline $\mathrm{SO}-4$ & I am too often caring for my friends on Facebook. & 0.817 \\
\hline SO-5 & $\begin{array}{l}\text { I pay too much attention to posts of my friends on } \\
\text { Facebook. }\end{array}$ & 0.813 \\
\hline SO-6 & $\begin{array}{l}\text { I congratulate Facebook friends as a consequence of a } \\
\text { birthday reminder, although I would not congratulate } \\
\text { them in real life. }\end{array}$ & 0.729 \\
\hline \multicolumn{3}{|c|}{ Disclosure (Mean: 3.89; Standard Deviation: 1.49) } \\
\hline D-1 & There is more information on Facebook than I can digest. & 0.729 \\
\hline D-2 & I receive too much information on Facebook. & 0.728 \\
\hline D-3 & The information on Facebook overextends me. & 0.869 \\
\hline D-4 & $\begin{array}{l}\text { It is difficult for me to focus on the essential information } \\
\text { on Facebook. }\end{array}$ & 0.868 \\
\hline \multicolumn{3}{|c|}{ Pattern (Mean: 2.89; Standard Deviation: 1.32) } \\
\hline$P-1$ & $\begin{array}{l}\text { Through Facebook, I am forced to inform friends about } \\
\text { news prompts. }\end{array}$ & 0.889 \\
\hline $\mathrm{P}-2$ & $\begin{array}{l}\text { Through Facebook, I am forced to communicate with } \\
\text { friends periodically. }\end{array}$ & 0.933 \\
\hline P-3 & $\begin{array}{l}\text { I am forced to adapt my communication patterns to } \\
\text { Facebook. }\end{array}$ & 0.832 \\
\hline \multicolumn{3}{|c|}{ Complexity (Mean: 2.65; Standard Deviation: 1.49) } \\
\hline Comp-1 & I need a long time to understand and use Facebook. & 0.899 \\
\hline Comp-2 & $\begin{array}{l}\text { I do not find enough time to upgrade my technology skills } \\
\text { to use Facebook. }\end{array}$ & 0.911 \\
\hline Comp-3 & $\begin{array}{l}\text { I do not know enough about Facebook to use it } \\
\text { satisfactorily. }\end{array}$ & 0.825 \\
\hline Comp-4 & I often find Facebook too complex to use. & 0.869 \\
\hline \multicolumn{3}{|c|}{ Uncertainty (Mean: 4.87; Standard Deviation: 1.28) } \\
\hline Unc-1 & $\begin{array}{l}\text { There are always new terms and conditions on } \\
\text { Facebook. }\end{array}$ & 0.864 \\
\hline Unc-2 & Facebook apps are constantly being changed. & 0.943 \\
\hline Unc-3 & Overall, Facebook is constantly being changed. & 0.931 \\
\hline
\end{tabular}


Invasion (Mean: 3.63; Standard Deviation: 1.68)

\begin{tabular}{|l|l|c|}
\hline Inv-1 & $\begin{array}{l}\text { I am in touch with my Facebook friends too much over } \\
\text { Facebook, even during my vacation. }\end{array}$ & 0.889 \\
\hline Inv-2 & $\begin{array}{l}\text { I sacrifice my vacation and weekend time to use } \\
\text { Facebook. }\end{array}$ & 0.933 \\
\hline Inv-3 & I feel my personal life is being invaded by Facebook. & 0.832 \\
\hline SNS distraction & \\
\hline
\end{tabular}

Think of situations when you are using Facebook (e.g. browsing, chatting etc.) and you find that using it becomes unpleasant. Please fill out the following according to what you would do in such a situation.

I take my mind off the current thing/activity by...

Distraction within SNS (Mean: 4.12; Standard Deviation: 1.56)

\begin{tabular}{|c|c|c|}
\hline DisSNS-1 & ... exploring new features on Facebook. & 0.876 \\
\hline DisSNS-2 & ... doing different actions on Facebook. & 0.933 \\
\hline DisSNS-3 & ... using different functions on Facebook. & 0.939 \\
\hline DisSNS-4 & ... using different features on Facebook. & 0.929 \\
\hline DisSNS-5 & ... by doing different tasks on Facebook. & 0.896 \\
\hline \multicolumn{3}{|c|}{ Distraction outside SNS (Mean: 2.75; Standard Deviation: 1.27) } \\
\hline DisNoSNS-1 & ... being with my family or friends. & 0.933 \\
\hline DisNoSNS-2 & $\begin{array}{l}\text {... doing other hobbies (such as walking, reading books, } \\
\text { watching TV). }\end{array}$ & 0.873 \\
\hline DisNoSNS-3 & $\begin{array}{l}\text {... using other IT applications / apps instead of Facebook } \\
\text { (e.g. Snapchat, WhatApp) }\end{array}$ & 0.835 \\
\hline DisNoSNS-4 & surfing on other sites than Facebook & 0.891 \\
\hline \multicolumn{3}{|c|}{ SNS addiction (Mean: 2.95; Standard Deviation: 1.30) } \\
\hline \multicolumn{3}{|c|}{ Please respond to each of the following statements } \\
\hline Add-1 & $\begin{array}{l}\text { I sometimes neglect important things because of my } \\
\text { interest in Facebook. }\end{array}$ & 0.892 \\
\hline Add-2 & $\begin{array}{l}\text { My social life has sometimes suffered because of me } \\
\text { using Facebook. }\end{array}$ & 0.903 \\
\hline Add-3 & $\begin{array}{l}\text { Using Facebook sometimes interferes with other } \\
\text { activities. }\end{array}$ & 0.887 \\
\hline Add-4 & When I am not using Facebook, I often feel agitated. & 0.813 \\
\hline Add-5 & $\begin{array}{l}\text { I have made unsuccessful attempts to reduce the time I } \\
\text { use Facebook. }\end{array}$ & 0.788 \\
\hline \multicolumn{3}{|c|}{\begin{tabular}{|l|} 
Please respond to each of the following statements \\
SNS use habit (Mean: $4.55 ;$ Standard Deviation: 1.66 )
\end{tabular}} \\
\hline Hab-1 & Using Facebook has become automatic to me. & 0.920 \\
\hline Hab-2 & Using Facebook is natural to me. & 0.919 \\
\hline Hab-3 & $\begin{array}{l}\text { When I want to interact with friends and relatives, using } \\
\text { Facebook is an obvious choice for me. }\end{array}$ & 0.775 \\
\hline Hab-4 & $\begin{array}{l}\text { When I want to have fun, using Facebook is an obvious } \\
\text { choice for me. }\end{array}$ & 0.934 \\
\hline \multirow{2}{*}{\multicolumn{3}{|c|}{ 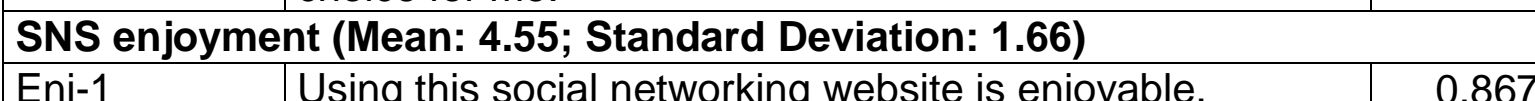 }} \\
\hline Enj-1 & & 0.867 \\
\hline
\end{tabular}




\begin{tabular}{|l|l|l|}
\hline Enj-2 & Using this social networking website is pleasurable. & 0.944 \\
\hline Enj-3 & Using this social networking website is fun. & 0.952 \\
\hline Enj-4 & Using this social networking website is exciting. & 0.939 \\
\hline Enj-5 & Using this social networking website is interesting. & 0.910 \\
\hline
\end{tabular}

Table 8: Construct Items and Loadings

\section{Appendix D: Common method bias}

In order to minimize the possibility of Common Methods Bias (CMB), we collected data at three different points in time. In addition, we used three techniques to determine the possible influence of CMB (Podsakoff et al. 2003). First of all, Harman's single factor test reveals whether the majority of the variance can be explained by one particular single factor. However, only 21.3 percent of the variance is explained by one single factor. Second, we used the procedure of examining the correlation matrix as specified by Pavlou et al. (2007). Extremely high correlations $(r>0.90)$ are an indicator of CMB but our correlation matrix did not indicate high correlation. Third, we used the ULMC approach to investigate the extent of CMB influence. We included a CMB factor to our primary research model and we transformed the factors in single-item constructs (Williams et al. 2003), so that we then compared the ratio of $\mathrm{R}^{2}$ with $\mathrm{CMB}$ to $\mathrm{R}^{2}$ without $\mathrm{CMB}$ factor. Results reveal that the average $\mathrm{R} 2$ with (without) the $\mathrm{CMB}$ is 0.739 (0.737). That is, the CMB factor explains an average difference (delta) of 0.002 , so that the resulting ratio of $\mathrm{R} 2$ without $\mathrm{CMB} / \mathrm{delta}$ is $1: 369.5$. The ratio of the path coefficients without $\mathrm{CMB}$ to the difference in path coefficients with and without CMB is 1:1190. Moreover, only four paths from the CMB factor to the single-item constructs are significant. Finally, there were no sign changes in any of the path coefficients after including the CMB variable. In summary, these results and the research approach indicate that $\mathrm{CMB}$ is not a substantial issue that might confound our results.

\section{Appendix E: Sample representativeness}

We took care to assess the representative-ness of our sample as described below. Our sample was from a European Union country classified as 'developed' by the United Nations. We thus assessed our sample with reference to a typical user of Facebook in a developed country along three criteria: age, gender-split, and number of hours of use. For age and gender we used information from the Facebook Ad Manager at the time of writing to get an indication of the different characteristics of the Facebook users in the country our study was conducted in.

1. Age: Table 9 illustrates the distribution of our survey participants and of Facebook users in the country we did our study in. As can be seen - the two distributions are similar. Furthermore, we did a chi-square to test the similarity of the two distributions. The pvalue was 0.99 , which indicates that the two samples are not independent. That is, they are similar. This indicates that our sample is representative for the population of Facebook users in the country we did our study in at the time of writing the paper. We also found additional support for other countries. The age of $93 \%$ of our respondents is between 20 and 70 years, and that of $91.2 \%$ is between 20 and 60 years. Various reports show that $95 \%$ of Facebook users are 18 and above and about $80 \%$ are between 18 and 55 and (see for example, http://jetscram.com/blog/industry-news/social-media-user-statistics-and-agedemographics-2014/). Such a distribution is broadly similar to that in our sample. Further, the average age of our sample is 35 years, while the average age from a similar country, the UK, is around 38, similar to our value. (See, for example, 
https://www.statista.com/statistics/507417/number-of-facebook-users-in-the-unitedkingdom-uk-by-age-and-gender/).

2. Gender split: Table 9 illustrates the gender split for our sample and of Facebook users in the country we did our study in at the time of writing. A chi-square test for comparison revealed a p-value of 0.893 , which again indicates that the two distributions are not independent. This indicates that our sample is very similar to the population of Facebook users in the country we did our study in at the time of writing the paper. Additional support for different countries could also be found. Our sample is split at 55\%:45\% (female:male), while the data from a similar country, the UK, suggests a 53\%:47\% (female:male) split for Facebook users. (See, for example, https://www.statista.com/statistics/507417/number-of-facebook-users-in-the-unitedkingdom-uk-by-age-and-gender/). They both are very similar.

3. Number of hours of Facebook use: We note that the average time spent on Facebook per day by our respondents is 64.5 minutes (Table 1). Our respondents were from an EU country classified in the United Nations 'developed' category. Anecdotal evidence suggests people in similar countries, e.g. the US, spend about 50 minutes a day on Facebook - https://www.nytimes.com/2016/05/06/business/facebook-bends-the-rules-ofaudience-engagement-to-its-advantage.html . The UK communications regulator, OfCom for example, reports that the average number of daily sessions of Facebook by the UK population is 12. (See https://www.ofcom.org.uk/data/assets/pdf_file/0021/105438/ukinternet-online.pdf.). Considering an average session to be of 5 minutes, which is a reasonable assumption, the total time is 60 minutes. While it is very hard to get an exact number, the above numbers, from two different countries are both close to 64 minutes, which is our average length of use per day.

\begin{tabular}{|l|l|c|c|}
\hline \multicolumn{2}{|c|}{ Characteristics } & $\begin{array}{c}\text { Facebook (collected from } \\
\text { Facebook Ad Manager) }\end{array}$ & Our Sample \\
\hline Age & $<20$ & $6.0 \%$ & $7.2 \%$ \\
\hline & $20-29$ & $29.7 \%$ & $26.8 \%$ \\
\hline & $30-39$ & $25.3 \%$ & $32.9 \%$ \\
\hline & $40-49$ & $17.1 \%$ & $18.4 \%$ \\
\hline & $50-59$ & $13.6 \%$ & $13.1 \%$ \\
\hline & $60-70$ & $8.2 \%$ & $1.6 \%$ \\
\hline Gender & male & $51.6 \%$ & $44.9 \%$ \\
\hline & female & $48.4 \%$ & $55.1 \%$ \\
\hline
\end{tabular}

Table 9 Age and gender of Facebook users in the country of our study and in our sample

\section{References}

Aghaz, A., and Sheikh, A. 2016. "Cyberloafing and job burnout: An investigation in the knowledge-intensive sector," Computers in Human Behavior (62), pp. 51-60.

Ayyagari, R., Grover, V., and Purvis, R. 2011. "Technostress: Technological Antecedents and Implications," MIS Quarterly (35:4), pp. 831-858.

Bagozzi, R. P. 1979. "The Role of Measurement in Theory Construction and Hypothesis

Testing: Toward a Holistic Model," in Conceptual and theoretical developments in 
marketing, O. C. Ferrell, S. W. Brown and C. W. Lamb (eds.), Chicago, Ill.: American Marketing Assoc., pp. 15-32.

Bala, H., and Venkatesh, V. 2015. "Adaptation to Information Technology: A Holistic Nomological Network from Implementation to Job Outcomes," Management Science (62:1), pp. 156-179.

Barki, H., Titah, R., and Boffo, C. 2007. "Information System Use-Related Activity: An Expanded Behavioral Conceptualization of Individual-Level Information System Use," Information Systems Research (18:2), pp. 173-192.

Barley, S.R. 1986. "Technology as an Occasion for Structuring: Evidence from Observations of CT Scanners and the Social Order of Radiology Departments," Administrative Science Quarterly (31:1), pp. 78-108.

Beaudry, A., and Pinsonneault, A. 2005. "Understanding user responses to information technology: a coping model of user adaptation," MIS Quarterly (29:3), pp. 493-524.

Beaudry, A., and Pinsonneault, A. 2010. "The Other Side of Acceptance: Studying the Direct and Indirect Effects of Emotions on Information Technology Use," MIS Quarterly (34:4), pp. 689-710.

Campbell, A., and Pisterman, S. 1996. "A Fitting Approach to Interactive Service Design: The Importance of Emotional Needs," Design Management Journals (7:4), pp. 10-14.

Carmines, E. G., and Zeller, R. A. 2008. Reliability and validity assessment, Newbury Park, Calif.: Sage Publ.

Chin, W. W., Gopal, A., and Salisbury, W.D. 1997. "Advancing the theory of adaptation structuration: The development of a scale to measure faithfulness of appropriation.," Information Systems Research (8:4), pp. 342-367.

Chiu, C.-M., Hsu, M.-H., Lai, H., and Chang, C.-M. 2012. "Re-examining the influence of trust on online repeat purchase intention: The moderating role of habit and its antecedents," Decision Support Systems (53:4), pp. 835-845.

Cooper, C. L., Dewe, P., and O'Driscoll, M. P. 2001. Organizational stress: A review and critique of theory, research, and applications, Thousand Oaks, Calif: Sage.

D'Arcy, J., Herath, T., and Shoss, M. K. 2014. "Understanding Employee Responses to Stressful Information Security Requirements: A Coping Perspective," Journal of Management Information Systems (31:2), pp. 285-318.

Davidson, E., and Pai, D. 2004. "Making Sense of Technological Frames: Promise, Progress, and Potential," in Information Systems Research, B. Kaplan, D. P. Truex, D. Wastell, A. T. Wood-Harper and J. I. DeGross (eds.), Boston: Kluwer Academic Publishers, pp. 473491.

de Guinea, A. O., and Markus, M. L. 2009. "Why Break the Habit of a Lifetime? Rethinking the Roles of Intention, Habit, and Emotion in Continuing Information Technology Use," MIS Quarterly (33:3), pp. 433-444.

de Guinea, A. O., and Webster, J. 2013. "An investigation of information systems use patterns: technological events as triggers, the effect of time, and consequences for performance," MIS Quarterly (37:4), pp. 1165-1188.

Dedyukhina, A. 2018. Homo Distractus. http://www.consciouslydigital.com/store/p7/homodistractus.

DeSanctis, G., and Poole, M. S. 1994. "Capturing the Complexity in Advanced Technology Use: Adaptive Structuration Theory,” Organization Science (5:2), pp. 121-147. 
Desouza, K. C., Awazu, Y., and Ramaprasad, A. 2007. "Modifications and Innovations to Technology Artifacts," Technovation (27:4), pp. 204-220.

Diette, G. B., Lechtzin, N., Haponik, E., Devrotes, A., and Rubin, H. R. 2003. "Distraction Therapy With Nature Sights and Sounds Reduces Pain During Flexible Bronchoscopy *," CHEST Journal (123:3), p. 941.

Dijkstra, T. K., and Henseler, J. 2015. "Consistent partial least squares path modeling," MIS Quarterly (39:2), pp. 297-316.

Duhachek, A. 2005. "Coping: A Multidimensional, Hierarchical Framework of Responses to Stressful Consumption Episodes," Journal of Consumer Research (32:1), pp. 41-53.

Edwards, J. R. 2001. "Multidimensional Constructs in Organizational Behavior Research: An Integrative Analytical Framework," Organizational Research Methods (4:2), pp. 144-192.

Fornell, C., and Larcker, D. F. 1981. "Evaluating structural equation models with unobservable variables and measurement error," Journal of Marketing Research (18:1), pp. 39-50.

Fox, J., and Moreland, J. J. 2015. "The dark side of social networking sites: An exploration of the relational and psychological stressors associated with Facebook use and affordances," Computers in Human Behavior (45), pp. 168-176.

Galluch, P. S., Grover, V., and Thatcher, J. B. 2015. "Interrupting the workplace: examining stressors in an information technology context," Journal of the Association for Information Systems (16:1), pp. 1-47.

Gartner 2011. Gartner Survey Highlights Consumer Fatigue with Social Media. http://www.gartner.com/it/page.jsp?id=1766814. Accessed 7 September 2011.

Griffiths, M. D. 2012. "Facebook addiction: Concerns, criticism, and recommendations," Psychological Reports (110:2).

Griffiths, M. D., and Parke, J. 2002. "The Social Impact of Internet Gambling," Social Science Computer Review (20:3), pp. 312-320.

Hair, J. F. 1995. Multivariate data analysis with readings, Englewood Cliffs, N.J: Prentice Hall.

Henseler, J., Dijkstra, T. K., Sarstedt, M., Ringle, C. M., Diamantopoulos, A., Straub, D. W., Ketchen, D. J., Hair, J. F., Hult, G. T. M., and Calantone, R. J. 2014. "Common Beliefs and Reality About PLS: Comments on Ronkko and Evermann (2013)," Organizational Research Methods (17:2), pp. 182-209.

Jarvis, C. B., MacKenzie, S. B., and Podsakoff, P. M. 2003. "A Critical Review of Construct Indicators and Measurement Model Misspecification in Marketing and Consumer Research," Journal of Consumer Research (30:2), pp. 199-218.

Jasperson, J., Carter, P.E., and Zmud, R. W. 2005. "Comprehensive Conceptualization Of Post-Adoptive Behaviors Associated With Information Technology Enabled Work Systems," MIS Quarterly (29:3), pp. 525-557.

Kim, E. J., Namkoong, K., Ku, T., and Kim, S. J. 2008. “The relationship between online game addiction and aggression, self-control and narcissistic personality traits," European psychiatry: the journal of the Association of European Psychiatrists (23:3), pp. 212-218.

Koroleva, K., Krasnova, H., Veltri, N., and Günther, O. 2011. "It's all about networking! Empirical investigation of social capital formation on social network sites," Proceedings of the international conference on information systems. 
Krasnova, H., Widjaja, T., Buxmann, P., Wenninger, H., and Benbasat, I. 2015. "Research Note - Why following friends can hurt you: an exploratory investigation of the effects of envy on social networking sites among college-age users," Information Systems Research (26:3), pp. 585-605.

Landis, J. R., and Koch, G. G. 1977. "The Measurement of Observer Agreement for Categorical Data," Biometrics (33:1), pp. 159-174.

Landsbergis, P. A. 1988. "Occupational stress among health care workers: A test of the job demands-control model," Journal of Organizational Behavior (9:3), pp. 217-239.

Law, K. S., Wong, C.-S., and Mobley, W.H. 1998. "Toward a Taxonomy of Multidimensional Constructs," Academy of Management Review (23:4), pp. 741-755.

Lazarus, R. S. 1966. Psychological stress and the coping process, New York, NY: McGrawHill.

Lazarus, R. S., and Folkman, S. 1984. Stress, appraisal, and coping, New York: Springer Pub. Co.

Limayem, M., and Hirt, S. G. 2003. "Force of Habit and Information Systems Usage: Theory and Initial Validation," Journal of the Association for Information Systems (4:1), pp. 6597.

Limayem, M., Hirt, S. G., and Cheung, C. M.K. 2007. "How Habit Limits the Predictive Power of Intention: The Case of Information Systems Continuance," MIS Quarterly (31:4), pp. 705-737.

Lyytinen, K., and Yoo, Y. 2002. "Research Commentary: The Next Wave of Nomadic Computing," Information Systems Research (13:4), pp. 377-388.

Maier, C., Laumer, S., Eckhardt, A., and Weitzel, T. 2015a. "Giving too much social support: Social overload on social networking sites," European Journal of Information Systems (24:5), pp. 447-464.

Maier, C., Laumer, S., Weinert, C., and Weitzel, T. 2015b. "The effects of technostress and switching stress on discontinued use of social networking services: a study of Facebook use," Information Systems Journal (25:3), pp. 275-308.

Maier, C., Laumer, S., Wirth, J., and Weitzel, T. 2019. "Technostress and the Hierarchical Levels of Personality: A Two-wave Study with Multiple Data Samples," European Journal of Information Systems.

McFedries, P. 2013. We're Being Driven to Distraction by Clamorous Computing. http://spectrum.ieee.org/computing/embedded-systems/were-being-driven-to-distractionby-clamorous-computing.

Morrison, D. E., and Firmstone, J. 2000. "The social function of trust and implications for ecommerce," International Journal of Advertising (19:5), pp. 599-623.

Nahm, A. Y., Solís-Galván, Rao, S. S., and Ragu-Nathan, T. S. 2002. "The Q-Sort Method: Assessing Reliability and Construct Validity of Questionnaire Items at a Pre-Testing Stage," Journal of Applied Statistics (1:1), pp. 114-125.

Nunnally, J. C., and Bernstein, I. H. 1994. Psychometric theory, New York: McGraw-Hill.

Orlikowski, W. J., and Gash, D. C. 1994. "Technological Frames: Making Sense of Information Technology in Organizations," ACM Transactions on Information Systems (12:2), pp. 669-702. 
Ouellette, J. A., and Wood, W. 1998. "Habit and intention in everyday life: The multiple processes by which past behavior predicts future behavior," Psychological Bulletin (124:1), pp. 54-74.

Pavlou, P. A., Liang, H., and Xue, Y. 2007. "Understanding and mitigating uncertainty in online exchange relationships: A principal-agent perspective," MIS Quarterly (31:1), pp. 105-136.

Podsakoff, P. M., MacKenzie, S. B., Lee, J.-Y., and Podsakoff, N. P. 2003. "Common Method Biases in Behavioral Research: A Critical Review and Recommended Remedies,' Journal of Applied Psychology (83:5), pp. 879-903.

Polites, G. L., and Karahanna, E. 2012. "Shackled to the status quo: The inhibiting effects of incumbent system habit, switching costs, and inertia on new system acceptance," MIS Quarterly (36:1).

Polites, G. L., Roberts, N., and Thatcher, J. 2012. "Conceptualizing models using multidimensional constructs: a review and guidelines for their use," European Journal of Information Systems (21:1), pp. 22-48.

Potenza, M. N. 2006. "Should addictive disorders include non-substance-related conditions?" Addiction (Abingdon, England) (101 Suppl 1), pp. 142-151.

Ragu-Nathan, T. S., Tarafdar, M., Ragu-Nathan, B. S., and Qiang, T. 2008. "The Consequences of Technostress for End Users in Organizations: Conceptual Development and Empirical Validation," Information Systems Research (1:4), pp. 417-433.

Rai, A., Patnayakuni, R., and Patnayakuni, N. 2006. "Firm Performance Impacts of Digitally Enabled Supply Chain Integration Capabilities,” MIS Quarterly (30:2), pp. 225-246.

Ringle, C. M., Wende, S., and Becker, J.-M. 2014. SmartPLS3, Hamburg.

Rogerson, P. A. 2015. Statistical methods for geography: A students guide, Los Angeles, London, New Delhi, Singapore, WashingtonDC: Sage.

Salisbury, W.D., Chin, W. W., Gopal, A., and Newsted, P. R. 2002. "Research report: Better theory through measurement- Developing a scale to capture consensus on appropriation.," Information Systems Research (13:1), pp. 91-103.

Sarstedt, M., and Mooi, E. 2019. A Concise Guide to Market Research, Berlin, Heidelberg: Springer Berlin Heidelberg.

Singletary, L.L.A., Akbulut, A. Y., and Houston, A.L. 2002. "Unanticipated Software Use by Adolescents Following Mandatory Adoption," ICIS 2002 Proceedings.

Stein, M.-K., Newell, S., Wagner, E. L., and Galliers, R. D. 2015. "Coping with information technology: Mixed emotions, vacillation and non-conforming use patterns," MIS Quarterly (39:2), pp. 367-392.

Tang, C. S.-K., and Oei, T. P. 2011. "Gambling cognition and subjective well-being as mediators between perceived stress and problem gambling: a cross-cultural study on White and Chinese problem gamblers," Psychology of addictive behaviors : journal of the Society of Psychologists in Addictive Behaviors (25:3), pp. 511-520.

Tarafdar, M., D'Arcy, J., Turel, O., and Gupta, A. 2015. "The dark side of information technology: Is overuse of information technology sapping your employees' productivity, innovation, and well-being?" MIT Sloan Management Review (56:2), pp. 60-70.

Tarafdar, M., and Davison, R. M. 2018. "Research in Information Systems: Intra-Disciplinary and Inter-Disciplinary Approaches," Journal of the Association for Information Systems $(19: 6)$ 
Tarafdar, M., Tu, Q., Ragu-Nathan, B., and Ragu-Nathan, T. 2007. "The Impact of Technostress on Role Stress and Productivity," Journal of Management Information Systems (24:1), pp. 301-328.

Tarafdar, M., Tu, Q., and Ragu-Nathan, T. S. 2010. "Impact of Technostress on End-User Satisfaction and Performance," Journal of Management Information Systems (27:3), pp. 303-334.

Traeger, L. 2013. "Distraction (Coping Strategy)," in Encyclopedia of Behavioral Medicine, M. D. Gellman and J. R. Turner (eds.), New York, NY: Springer New York, pp. 610-611.

Turel, O. 2015. "Quitting the use of a habituated hedonic information system: A theoretical model and empirical examination of Facebook users," European Journal of Information Systems (24:4), pp. 431-446.

Turel, O., and Serenko, A. 2012. "The benefits and dangers of enjoyment with social networking websites," European Journal of Information Systems (21:5), pp. 512-528.

Turel, O., Serenko, A., and Giles, P. 2011. "Integrating Technology Addiction and Use: An Empirical Investigation of Online Auction Users," MIS Quarterly (35:4), pp. 1043-1061.

Vaast, E., and Walsham, G. 2005. "Representations and actions: the transformation of work practices with IT use," Information and Organization (15:1), pp. 65-89.

Vaghefi, I., Lapointe, L., and Boudreau-Pinsonneault, C. 2016. "A typology of user liability to IT addiction," Information Systems Journal, pp. n/a.

Verplanken, B., and Aarts, H. 1999. "Habit, Attitude, and Planned Behaviour: Is Habit an Empty Construct or an Interesting Case of Goal-directed Automaticity?" European review of social psychology (10:1), pp. 101-134.

Verplanken, B., and Orbell, S. 2003. "Reflections on Past Behavior: A Self-Report Index of Habit Strength,” Journal of Applied Social Psychology (33:6), pp. 1313-1330.

Weinschenk, S. 2012. Why We're All Addicted to Texts, Twitter and Google. https://www.psychologytoday.com/blog/brain-wise/201209/why-were-all-addicted-textstwitter-and-google.

Williams, L. J., Edwards, J.R., and Vandenberg, R.J. 2003. "Recent Advances in Causal Modeling Methods for Organizational and Management Research," Journal of Management (29:6), pp. 903-936.

Wood, W., Quinn, J. M., and Kashy, D. A. 2002. "Habits in everyday life: Thought, emotion, and action," Journal of Personality and Social Psychology (83:6), pp. 1281-1297.

Wrosch, C., Amir, E., and Miller, G. E. 2011. "Goal adjustment capacities, coping, and subjective well-being: the sample case of caregiving for a family member with mental illness," Journal of Personality and Social Psychology (100:5), pp. 934-946.

$\mathrm{Xu}, \mathrm{Z}$., Turel, O., and Yuan, Y. 2012. "Online game addiction among adolescents: Motivation and prevention factors," European Journal of Information Systems (21:3), pp. 321-340.

Young, K. S. 1998. "Internet Addiction: The Emergence of a New Clinical Disorder," CyberPsychology \& Behavior (1:3), pp. 237-244. 